\title{
OUTDOOR LEARNING WITH MOBILE TECHNOLOGY: A SYSTEMATIC REVIEW
}

\author{
Johan Stymne. \\ Stockholm University, Department of Computer and Systems Sciences, DSV. \\ SE-164 07 Stockholm, Sweden
}

\begin{abstract}
In outdoor learning with mobile technology, students use mobile technology for learning in an outdoor setting, for example in a park or a garden. To understand how mobile technology has been used in outdoor learning, a systematic review was carried out. A number of reviews on mobile learning and on specific sub-areas of mobile learning, such as language learning or computer education have been published in scientific journals and at conferences. So far, however, no systematic review has focused on outdoor learning with mobile technology. To guide the review the following research questions were posed: "Which are the educational subjects and educational levels in outdoor learning with mobile technology?" and "What types of technologies for positioning or navigation, augmentation, and methods for data collection and annotation are used in outdoor learning with mobile technology?". In total 87 articles, published between 2004 and 2019 were included in this review. Conclusions were that biology was the most common subject, primary or elementary school the most common educational levels, GPS was the major technology used for positioning and navigation, AR was the most common technology used for augmenting the outdoor learning environment, and taking photos and taking notes were the most common methods for data collection in outdoor learning with mobile technology. Building on the conclusions of this review and on previous reviews, suggestions are made for future research.
\end{abstract}

\section{KEYWORDS}

Outdoor Learning, Mobile Learning, Mobile Technology, Systematic Review, State of the Art

\section{INTRODUCTION}

One type of outdoor learning, which can be referred to as fieldwork and outdoor visits, is focused on undertaking learning activities, and is often linked to one or more curriculum subjects (Rickinson et al., 2004). In this type of outdoor learning, the learning activities could be supported by mobile technology (Suárez et al., 2018, Tan et al., 2018). Research in this area, outdoor learning with mobile technology, is the focus of this review. 
The interest in learning with mobile technology, or mobile learning, in education is increasing (Crompton et al., 2017). With this increased interest, the number of research studies on outdoor learning with mobile technology is also increasing. To get an updated understanding how mobile technology has been used in outdoor learning, a systematic review of research in this area was carried out.

So far, few reviews intended to cover the whole research field of mobile learning have been published. Two examples of general reviews of mobile learning research are from Frohberg et al. (2009) and Wingkvist \& Ericsson (2011). Frohberg et al. (2009) focused their analysis of 102 research projects on five dimensions: context, tools, control, communication, subject and objective. Wingkvist \& Ericsson (2011) reviewed 114 articles from the World Conference on Mobile and Contextual Learning (mLearn) 2005, 2007 and 2008, focusing their analysis on research purpose and research method. With the growth of the research field of mobile learning these general reviews have given way for more specific reviews. In recent years, reviews on different aspects of the mobile learning research field are beginning to appear, such as Almeida \& Araújo Jr (2016) focusing on science and mathematics, Crompton et al. (2016) focusing on science, Anohah et al. (2017) focusing on computer education, Kukulska-Hulme and Viberg (2018) focusing on second language acquisition, Crompton et al. (2017) focusing on educational levels from pre-kindergarten to grade 12, and Suárez et al. (2018) focusing on mobile inquiry-based learning.

Many reviews on outdoor learning have been published (e.g. Rickinson et al. (2004), and Fiennes et al. (2015)). However, so far only one review has focused on outdoor learning with mobile technology; Tan et al. (2018). They focused on a specific type of learning: inquiry-based learning in outdoor settings, and included research from only two countries: The Netherlands and Singapore.

So far there has been no systematic review focusing on outdoor learning with mobile technology. In identifying gaps in previous research, Crompton et al. (2017) also suggested that there is a need for more reviews on mobile learning to add to their review and to the research area: "Further reviews are needed to build on this study and add to the paucity of research in this area." (p. 61). To summarise, there have been a number of reviews on mobile learning in general and on specific subject areas such as second language acquisition or on specific learning approaches such as inquiry-based learning, however no systematic review has focused specifically on outdoor learning with mobile technology.

To guide the review the following two research questions are posed:

- Which are the educational subjects and educational levels in outdoor learning with mobile technology?

- What types of technologies for positioning or navigation, augmentation, and methods for data collection and annotation are used in outdoor learning with mobile technology?

Answers to the first question, on educational subjects and educational levels, allows for comparisons with results from earlier reviews on mobile learning. The second question adds to earlier reviews on mobile learning by focusing on how mobile technology is used in outdoor learning, more specifically by asking what technologies students use for positioning and navigation, what technologies students use for augmenting especially the physical environment, and how students collect data and annotate data in the field. Both questions contribute to forming a state-of-the-art as the review includes research until the end of 2019.

This review may be of interest to researchers, educators, funding agencies, and other stakeholders as it also identifies both common approaches and gaps in current research on outdoor learning with mobile technology. 


\section{BACKGROUND}

Outdoor learning with mobile technology has two concepts that need to be described further: outdoor learning and mobile technology. In reviewing research on outdoor learning, Rickinson et al. (2004) distinguishes between three main types of outdoor learning activities:

1. fieldwork and visits to field study centres, nature centres, farms, parks or gardens

2. outdoor adventure education in local or distant settings

3. projects in school grounds or the local community. (p. 9)

The first type has a focus on: "undertaking learning activities, often linked with particular curriculum subjects", the second has a focus on: "participation in outdoor adventurous activities", and the third has: "a range of curricular, cross-curricular and/or extra-curricular purposes" (p. 16). Both the name and the focus of the first type of outdoor learning is in line with this review. Tan et al. (2018) argues that outdoor learning allows students to learn by interacting with the physical environment: "Learning in the authentic outdoor environment enables students to leverage on the physical affordances of the real-world platform in the meaning-making process." (p. 25). This emphasis on making use of the physical environment in learning activities is also in line with this review.

The second concept, mobile technology, can be derived from a definition of mobile learning. One often referred to definition, from Sharples et al. (2007), suggests that mobile learning is: "the processes of coming to know through conversations across multiple contexts amongst people and personal interactive technologies" (p. 224). Given this definition, mobile technology can be described as personal interactive technology supporting interaction between people and across multiple contexts. This description of mobile technology is adopted for this review.

From the recent reviews of mobile learning, three reviews were the most relevant to the current review, as these reviews have a wider focus than one or two educational subjects and an international scope. These three reviews were: Crompton et al. (2016), Crompton et al. (2017), and Suárez et al. (2018).

In a review of mobile learning in science education, Crompton et al. (2016) reviewed 49 articles from 2000 onwards. Among the presented results are which science area the studies belong to, educational level, countries of study, and types of mobile devices. The most common science area was life science (67\%), including for example biology. The most common educational level was elementary school (53\%) followed by high school (22\%). Taiwan (43\%), followed by USA (16\%), were the most common countries or regions. Mobile phones and PDAs were the most common mobile devices (30\% each). $15 \%$ was reported as mobile devices in general, digital camera made up 9\%, iPad 5\%, and handheld, tablet and iTouch had a share of $4 \%$ each. In the discussion they note that the specific type of mobile phone or PDA was rarely mentioned in the articles, or even just mentioned as mobile device or handheld. Crompton et al. (2016) did not identify any specific mobile device as the most common, which led them to suggest that the type of device is not important for future studies: "...those interested in doing future research regarding the use of mobile technologies need not focus on the specific type of mobile device, but rather on the multifunctionality and accessibility of the device." (p. 158).

In another review, Crompton et al. (2017) reviewed 113 articles on mobile learning from pre-kindergarten to grade 12 (PK-12), from 2010 to 2015. The results show, for example, that the most common subject area was science $(56 \%)$, followed by literacy $(21 \%)$, and mathematics $(10 \%)$. The most common educational level was elementary school $(46 \%)$, followed by middle school (29\%), and high school (19\%). The most common mobile device was mobile phone 
(34\%), followed by PDA (22\%), tablet (16\%), iPad (11\%), ebook (2\%), and iPod (1\%). Taiwan $(35 \%)$ was the most common country or region, followed by Singapore (9\%), and USA (8\%).

Crompton et al. $(2016,2017)$ present clear results on the educational contexts of mobile learning in science and mobile learning in PK-12 education, and which mobile devices are used. There is a knowledge gap, however, in what the mobile devices are used for, for example positioning, augmentation or for collecting data in the field. There is also a knowledge gap in what the educational subjects and educational levels are specifically for outdoor learning with mobile technology.

Suárez et al. (2018) reviewed 62 studies on mobile inquiry-based learning from 2006 to April 2016. They extracted data in five categories: direct instruction, access to content, data collection, peer-to-peer communication, and contextual support. In their results, location guidance was the most common type of direct instruction. Location guidance, by using for example GPS, RFID or QR codes, was reported in 27 of the 62 studies. Digital artifacts triggered by GPS and AR was reported as fixed content, as part of the access to content category. Fixed content was reported in 25 of the studies. For the data collection category, taking pictures, taking notes, recording video, and recording audio were all described as cooperative data collection. Cooperative data collection was the most common type of data collection, reported in 57 of the studies. In a meta-analysis they mapped the five categories to six types of agency supported by the mobile technology in inquiry-based learning. One result of the review and meta-analysis is an overview of what kind of learner agency can be supported by different parts of a mobile inquiry-based learning activity.

Suárez et al. (2018) present their results clearly on how technologies like GPS, AR and taking notes on mobile devices are used in mobile inquiry-based learning. There is a knowledge gap, however, in what mobile technologies and methods are used in other types of outdoor learning. A systematic review could contribute to filling this knowledge gap.

\section{METHOD}

A systematic review was conducted, based on the PRISMA statement (Liberati et al., 2009). The PRISMA statement includes guidelines for reporting of systematic reviews of interventions. This systematic review follows Liberati et al. (2009) in that it presents which information sources were used, search strategy, study selection, and data collection process. The information sources used were research databases and conference proceedings. The search strategy used both keyword search and manual search. The study selection used six selection criteria and three inclusion and exclusion criteria. The data collection process used eight categories for data extraction.

\subsection{Database Selection and Search Strategy}

Database searches were carried out using ERIC via EBSCOhost, Scopus and DBLP. The Title, Abstract and Keyword fields were included in this search. As a complement the main conferences focusing on mobile learning were selected for free text search: World Conference on Mobile and Contextual Learning (mLearn), and the International Conference on Mobile Learning. 
The search strategy used was a combination of keyword search using databases, manual search and reference list search. Two sets of keywords were used in the keyword search; outdoor learning-related keywords and mobile technology-related keywords. The outdoor learning-related keywords were identified from outdoor learning reviews: Rickinson et al. (2004), and Fiennes et al. (2015), and the mobile technology-related keywords were identified from previous mobile learning reviews: Frohberg et al. (2009), Wingqvist \& Ericsson (2011), and Crompton et al. (2016, 2017).

As the articles should include both outdoor learning and mobile technology the search was done using the following combination of outdoor learning-related keywords and mobile technology-related keywords:

- $\quad$ ERIC, Scopus (Title, Author keywords, Abstract): ("outdoor * learning*" OR "outdoor * lesson*" OR "outdoor* education*" OR "fieldwork*" OR "field trip*" OR excursion* OR adventur* OR "nature visit*" OR bushcraft*) AND ("mobile learning" OR m-learning OR "mobile phone*" OR "mobile device*" OR "mobile technolog*" OR smartphone OR handheld OR pda* OR "augmented reality").

- $\quad$ DBLP (Title, Author keywords, Abstract): Manual combination of the keywords.

- World Conference on Mobile and Contextual Learning (Full text), International Conference on Mobile Learning (Title, Author keywords, Abstract): Manual combination of the outdoor learning-related keywords without wildcards.

\subsection{Selection Criteria}

The overall focus for the review was: "Original empirical research on outdoor learning with mobile technology", see Table 1. The articles were published between 2004 and 2019. This timeframe was chosen because the first studies on outdoor learning with mobile technology identified were published in 2004, and the selection includes articles published until December 2019. The geographical scope was international. All educational levels were included, ranging from pre-kindergarten to higher education including postgraduate level. Articles from all countries were included in the search, however only articles published in English were included in the selection. Only published articles that had been peer-reviewed were included.

Table 1. Description of selection criteria

\begin{tabular}{|l|l|}
\hline Criterium & Description \\
\hline Overall focus & Original empirical research on outdoor learning with mobile technology \\
\hline Timeframe & $2004-2019$ \\
\hline Educational level & Pre-kindergarten to Higher education \\
\hline Geographical scope & International \\
\hline Language & Articles published in English \\
\hline Sources & Published articles, Peer-reviewed \\
\hline
\end{tabular}

\subsubsection{Inclusion and exclusion criteria}

- For articles reporting on the same empirical study, only the last published article was included in the review. 
- Included articles needed to present results from empirical trials with representative learners using some mobile technology. This means that articles presenting results from trials with colleagues, or focusing on performance, technical functionality or usability of a system without also focusing on mobile learning were excluded.

- Only articles presenting studies where some aspect of the mobile technology, hardware or software, was designed for a specific learning activity were included. Studies using off-the-shelf mobile technology or with apps not intended for specific learning activities were excluded. Studies using only laptop computers were also excluded.

\subsection{Study Selection}

643 articles were identified through database search and manual search: ERIC (118), Scopus (414), DBLP (18), World Conference on Mobile and Contextual Learning (63), International Conference on Mobile Learning (11). After duplicates removal and screening 145 articles remained. In the end, 87 articles met the criteria for inclusion and were included in this review.

\subsection{Data Extraction}

The following data was extracted from the published articles: name of study, educational subject(-s), educational level(-s), country or region, mobile device(-s), technology used for positioning or navigation, technology used for augmenting the outdoor learning environment, and method(-s) used for data collection or annotation with mobile technology in outdoor learning. The extracted data is described in Table 2. For the full list of articles with extracted data, see appendix A.

Table 2. Description of extracted data

\begin{tabular}{|l|l|}
\hline Data & Description \\
\hline Name & $\begin{array}{l}\text { Name of study, or where not available, Name of project or } \\
\text { system or course }\end{array}$ \\
\hline Educational subject(-s) & Educational subject(-s) \\
\hline Educational level(-s) & $\begin{array}{l}\text { Pre-kindergarten, kindergarten and pre-school (typical age } \\
1-6 \text { years old), primary school or elementary school (6-12) } \\
\text { secondary school or middle school (12-16), high school } \\
(16-18), \text { higher education (18+) }\end{array}$ \\
\hline Country or region & Country or region where the empirical study took place \\
\hline Mobile device(-s) & Mobile phone, PDA, Tablet \\
\hline $\begin{array}{l}\text { Technology used for positioning or } \\
\text { navigation }\end{array}$ & GPS, QR, RFID, WIFI, Compass, Numerical code \\
\hline Technology used for augmenting & AR (Augmented Reality), 3D model, Image recognition \\
\hline $\begin{array}{l}\text { Method(-s) for data collection or } \\
\text { annotation }\end{array}$ & Photo, Notes, Audio, Video, Probe \\
\hline
\end{tabular}

The name of the study was not always reported in the articles. In those cases the name of the project, the name of the system, or the name of the course was extracted.

The educational levels differ from country to country. That is why some educational levels have two or more names. Differences in educational levels are also the reason why typical ages are given instead of exact ages. No inter-rater reliability check was performed. 


\section{RESULTS}

To give a backdrop to the results, the number of articles per year and per country or region are presented. The number of articles per year on outdoor learning with mobile technology increased, from two articles, which was the lowest number, in 2004, 2006 and 2007 to nine, which was the highest number, in 2015 and 2018, see Table 3.

Table 3. Number of articles per year

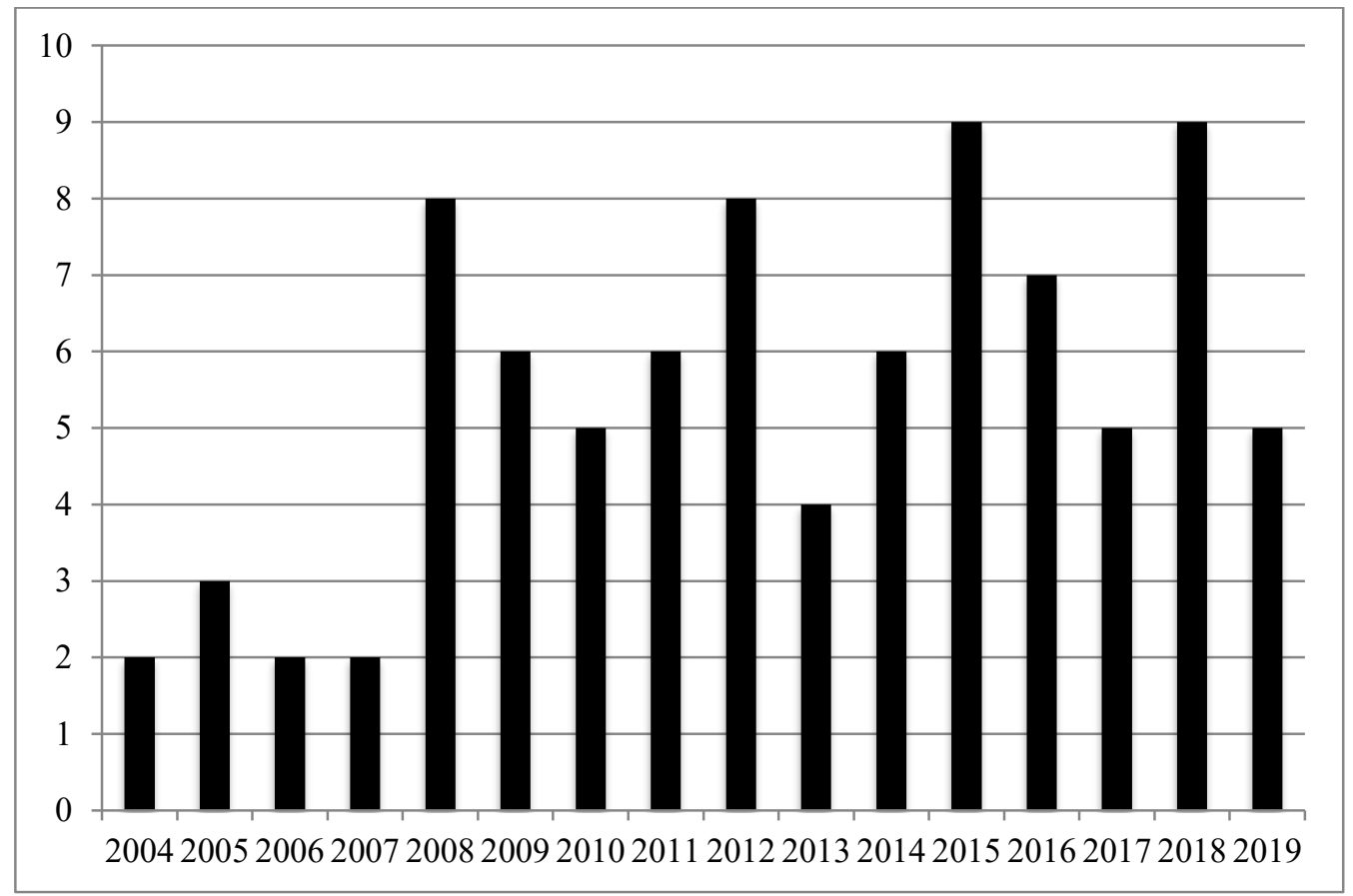

The top seven countries or regions to publish on outdoor learning with mobile technology were (number of articles in parenthesis): Taiwan (26), UK (7), Sweden (6), USA (6), Germany (5), Singapore (5), and Finland (4), see Table 4.

Table 4. Number of articles for the top seven countries or regions, and years of publication

\begin{tabular}{|l|c|c|}
\hline Country or region & Number of articles & $\begin{array}{c}\text { Years of } \\
\text { publication }\end{array}$ \\
\hline Taiwan & 26 & $2005-2019$ \\
\hline UK & 7 & $2004-2012$ \\
\hline Sweden & 6 & $2008-2015$ \\
\hline USA & 6 & $2011-2018$ \\
\hline Germany & 5 & $2005-2018$ \\
\hline Singapore & 5 & $2007-2015$ \\
\hline Finland & 4 & $2012-2018$ \\
\hline
\end{tabular}


Out of the 87 articles in this review, $30 \%$ were from Taiwan. The articles from Taiwan were published between 2005 and 2019. The articles from the UK were published from 2004, however the last article was published in 2012. The articles from Sweden were published between 2008 and 2015, and from USA between 2011 and 2018. The articles from Germany were published between 2005 and 2018, from Singapore between 2007 and 2015, and from Finland between 2012 and 2018.

There were articles from 16 more countries or regions: Greece (3), Israel (3), Japan (3), Brazil (2), Hong Kong (2), Italy (2), Portugal (2), Spain (2), Australia (1), Austria (1), Czech Republic (1), Estonia (1), Indonesia (1), Ireland (1), Norway (1), South Africa (1), and The Netherlands (1). The corresponding numbers for continents were: Asia (40), Europe (37), North America (6), South America (2), Africa (1), and Australia (1).

\subsection{Educational Subjects and Educational Levels}

The six most common subjects in the reviewed articles were (number of articles in parenthesis): biology (38), history (14), mathematics (9), language (7), geography (5) and geology (5) (see Table 5). The biology subject, reported in 38 articles, was much more common than any of the other subjects. Subjects reported in 1-4 articles were (number of articles in parenthesis): natural science (4), local culture (3), orientation (3), information and communication technology (ICT) (2), science (2), health education (2), physics (2), sustainability (2), tourism (2), archaeology (1), computer science (1), economy (1), pedagogy (1), and technology (1).

Biology was also the only subject reported on in articles from the first year of the review until the last year, 2004-2019. History, mathematics and geology were represented until 2019, while language and geography were represented in the middle of the timeframe for the review: 2008-2015 and 2005-2013.

Table 5. Six most common subjects, number of articles and years of publication

\begin{tabular}{|l|l|l|}
\hline Subject & Number of articles & Years of publication \\
\hline Biology & 38 & $2004-2019$ \\
\hline History & 14 & $2008-2019$ \\
\hline Mathematics & 9 & $2006-2019$ \\
\hline Language & 7 & $2008-2015$ \\
\hline Geography & 5 & $2005-2013$ \\
\hline Geology & 5 & $2008-2019$ \\
\hline
\end{tabular}

Primary school or elementary school was the most common educational level with 49 articles, see Table 6. 22 articles were from secondary school or middle school. 18 articles were from higher education. No articles were from pre-kindergarten, kindergarten and pre-school.

Table 6. Number of articles and educational levels

\begin{tabular}{|l|c|c|c|c|c|}
\hline Year & $\begin{array}{c}\text { Number } \\
\text { of articles }\end{array}$ & $\begin{array}{c}\text { Pre-kindergarten, } \\
\text { kindergarten and pre- } \\
\text { school }\end{array}$ & $\begin{array}{c}\text { Primary or } \\
\text { elementary } \\
\text { school }\end{array}$ & $\begin{array}{c}\text { Secondary } \\
\text { or middle } \\
\text { school }\end{array}$ & $\begin{array}{c}\text { Higher } \\
\text { education }\end{array}$ \\
\hline $2004-2019$ & 87 & 0 & 49 & 22 & 18 \\
\hline
\end{tabular}




\subsubsection{Country or Regional Comparison}

One difference between countries or regions was the subject reported in the articles. For example, the most common subject in Taiwan was biology. The subject was studied in 16 out of the 26 articles from Taiwan. The second most common subject in Taiwan, history was studied in four out of the 26 articles. Biology was also the most common subject in Germany, Singapore and Finland. In Sweden the most common subject was mathematics and in USA the most common was natural science. In the UK biology and language were as common, studied in two articles each.

Another difference between countries was the educational level of participating students. For example, the most common educational level in Taiwan was elementary school. Elementary school was reported in 23 out of the 26 articles. Primary or elementary school was also the most common in (number of articles in parenthesis): Sweden (6), USA (3), Singapore (4) and Finland (2). Secondary school was the most common in the UK (3), and in Germany (3). Higher education was not the most common educational level in any of the top seven countries, however it was the second most common educational level in Taiwan (2), the UK (2), USA (2), Germany (2), and Finland (1). All students from higher education were undergraduate students, and no students were from the graduate level.

One last difference between countries or regions was the size of student groups, ranging from one student, learning individually, to nine students in a group. Out of the top seven countries or regions, the most common group size in Taiwan and Singapore was one student, corresponding to individual learning. This group size was reported in 20 out of the 26 articles from Taiwan. The second most common group size for Taiwan was five students in each group. This group size was reported in four of the 26 articles. In the UK and USA, the most common group size was two students, in Sweden it was three students and in Germany and Finland it was two or three students.

\subsection{Mobile Devices}

Mobile phones were the most common mobile devices, see Table 7. The use of PDAs has decreased. PDAs were used in 18 articles between 2004 and 2011 and in four articles between 2012 and 2019. However, the use of mobile phones has increased in the same time period, going from 17 between 2004 and 2011 to 32 between 2012 and 2019. The use of tablets has also increased, going from two between 2004 and 2011 to 20 between 2012 and 2019.

Mobile phones are used in much the same way as PDAs in mobile learning, and have gradually replaced them. DVD or smart watch was not part of the data extraction, however a portable DVD player was used as mobile device in one of the reviewed articles. Smart watch was not used in any of the reviewed articles.

Table 7. Number of mobile phones, PDAs and tablets (two or more mobile devices in six articles)

\begin{tabular}{|l|c|c|c|c|}
\hline Year & Number of articles & Mobile phone & PDA & Tablet \\
\hline $2004-2011$ & 34 & 17 & 18 & 2 \\
\hline $2012-2019$ & 53 & 32 & 4 & 20 \\
\hline Total & 87 & 49 & 22 & 22 \\
\hline
\end{tabular}


Mobile phones, PDAs and tablets were used both individually and in groups of two or more students, see Table 8. Mobile phones or PDAs were used in 26 articles where the group size was one student, and in 41 articles where the group size was two or more students. Similarly mobile phones, PDAs and tablets were used in two articles with one student per group and in four articles with two or more students per group. Tablets were used in eight articles with one student per group and in nine articles with two or more students per group.

Table 8. Group size compared to type of mobile device

\begin{tabular}{|l|c|c|c|}
\hline Group size & $\begin{array}{c}\text { Mobile phone or } \\
\text { PDA }\end{array}$ & $\begin{array}{c}\text { Mobile phone or } \\
\text { PDA, and tablet }\end{array}$ & Tablet \\
\hline 1 & 26 & 2 & 8 \\
\hline 2 or more & 41 & 4 & 9 \\
\hline
\end{tabular}

\subsection{Positioning or Navigation Technologies}

Technologies for positioning or navigation to learning material were used in 65 articles. One such technology was used in 55 articles. Two were used in ten articles. No article reported on using three or more technologies for positioning or navigation. In the remaining 22 articles there was no report on using any technology for positioning or navigation.

GPS was the most common technology, see Table 9. It was reported in 46 articles, published between 2004 and 2019.

Table 9. Positioning or navigation technology used, with number of articles and years of publication

\begin{tabular}{|l|c|c|}
\hline Positioning or navigation technology & Number of articles & Years of publication \\
\hline GPS & 46 & $2004-2019$ \\
\hline QR & 17 & $2007-2018$ \\
\hline RFID & 7 & $2007-2019$ \\
\hline WIFI & 3 & 2005 and 2008 \\
\hline Compass & 3 & 2012,2015 and 2019 \\
\hline Numerical code & 2 & 2008 and 2015 \\
\hline
\end{tabular}

GPS was commonly used for guiding students through the learning activity. One example is the GeM project (Eliasson et al., 2011), where students were given tasks on their mobile phones when arriving at a new location. They also used GPS to measure the distance between two mobile phones on the opposite end of a field. They then used the distance to calculate large areas, for example a rectangle of $4000 \mathrm{~m}^{2}$. The second most common technology for positioning or navigation was QR codes, with 17 articles, published between 2007 and 2018. One example is the Context-aware mobile learning system (Chen et al., 2016), where students used QR codes placed near plants on the school campus to identify the plants.

The third most common technology was RFID, with 7 articles, published between 2007 and 2019. WIFI networks were used in three articles, published in 2005 and in 2008, and compass was used in three articles, published in 2012, 2015 and 2019. A numerical code is typed in manually to get the current position. Numerical codes were used in two articles, published in 2008 and 2015. 


\subsection{Augmenting Technologies}

Technologies for augmenting the outdoor learning environment were used in 20 articles. One such technology was used in 14 articles. Two were used in six articles. No article reported on using three technologies for augmenting the outdoor learning environment. In the remaining 67 articles there was no report on using any technology for augmenting the outdoor learning environment.

AR was the most common technology, see Table 10.

Table 10. Augmenting technology used, with number of articles and years of publication

\begin{tabular}{|l|c|c|}
\hline Augmenting technology & Number of articles & Years of publication \\
\hline AR & 14 & $2009-2019$ \\
\hline 3D model & 9 & $2008-2019$ \\
\hline Image recognition & 3 & $2005-2012$ \\
\hline
\end{tabular}

AR was used in 14 articles published between 2009 and 2019. AR was used in seven articles in the last two years, 2018-2019, the same numbers as in the previous years of the review. One example of AR is from Chien et al. (2019), where students scanned AR markers placed near or on plants on the school campus to see 3D images of the plants. The second most common technology was 3D models, with 9 articles, published between 2008 and 2019. One example is from Chin et al. (2019), where college students used an AR-based mobile learning system for learning about historical buildings. The students could use their mobile phones to manipulate 3D models, accessed by scanning information signs or other physical objects near the buildings. The third most common technology was Image recognition, with 3 articles, published between 2005 and 2012. One example is the EduPARK project (Pombo and Marques, 2019), where students and visitors to a local park used AR to learn about historical and regional issues, using image recognition of historical tiles as markers.

\subsection{Methods for Data Collection or Annotation}

In 48 articles, students used methods for collecting data or making annotations. One such method was used in 18 articles. Two were used in 21 articles. Three were used in eight articles. Four ware used in 1 article. No article reported on using five methods. In the remaining 39 articles there was no report on using any method for collecting data or making annotations.

The most common method students used for collecting data in the field was taking photos, and the most common method for annotation was taking notes, see Table 11.

Taking photos was used in 40 articles, published between 2005 and 2019. One example is the Nature Tour (Rikala, 2015), where students took photos of species, for example different kinds of red berries, to be able to identify trees close to the school campus. Taking notes on mobile technology was used in 20 articles, published between 2005 and 2018. The third most common method was recording audio, with 13 articles, published between 2008 and 2018. One example is the Participate project (Woodgate et al., 2008), where students recorded sound and took photos of the environment on their daily journeys between home and school, which could then be visualized on a map. 
Table 11. Methods for data collection or annotation, with number of articles and years of publication

\begin{tabular}{|l|c|c|}
\hline $\begin{array}{l}\text { Methods for data } \\
\text { collection or annotation }\end{array}$ & $\begin{array}{c}\text { Number of } \\
\text { articles }\end{array}$ & $\begin{array}{c}\text { Years of } \\
\text { publication }\end{array}$ \\
\hline Photo & 40 & $2005-2019$ \\
\hline Notes & 20 & $2005-2018$ \\
\hline Audio & 13 & $2008-2018$ \\
\hline Video & 10 & $2008-2019$ \\
\hline Probe & 6 & $2004-2018$ \\
\hline
\end{tabular}

The fourth most common method was recording video, with 10 articles, published between 2008 and 2019. The fifth most common method was probing the physical environment, for example by using specific mobile technology for measuring water quality, air temperature or carbon monoxide. Probes were used in 6 articles, published between 2004 and 2018. One example is Ambient Wood (Rogers et al., 2004), where students used a probe tool to measure light and moisture in a physical woodland. They could point the probe tool in the air in the ground or anywhere they liked to get a reading of light and moisture.

\section{DISCUSSION AND CONCLUSION}

One interpretation of the increasing number of articles published per year is that the interest in outdoor learning with mobile technology is still growing. In the first few years of this review, there were between two and three studies published on outdoor learning with mobile technology, whereas in the last few years of the review there were between five and nine studies published each year.

Most of the articles in this review were from Taiwan. This is in line with the results of the review of mobile learning in science by Crompton et al. (2016), who found that Taiwan was the most common country or region of study. It is also in line with the results of Crompton et al. (2017), who reviewed mobile learning in PK-12 education, finding that Taiwan had the highest number of publications. One difference was that the second most common country or region of study in this review was the UK compared to USA in second place in Crompton et al. (2016) and Singapore in Crompton et al. (2017). Notable is that the UK has the second highest number of articles published on outdoor learning with mobile technology, even though the last publication from the UK is from 2012.

Mobile phones or PDAs were the most common mobile devices. This is in line with the results of Crompton et al. (2016, 2017). The use of tablets has increased during the last eight years. Even though tablets have larger screen size, they were not predominantly used with group sizes of two or more students. Mobile phones, PDAs and tablets were used both for individual learning and when two or more students learned together. This adds to the suggestion by Crompton et al. (2016), that the type of mobile device does not matter, but rather that mobile devices have many functions and are easily accessible to students.

The first research question: "Which are the educational subjects and educational levels in outdoor learning with mobile technology?" can be answered with the following: The most common educational subject for outdoor learning with mobile technology was biology followed by history and mathematics. That biology was the most common subject is in line with Crompton et al. (2016). The most common educational level for outdoor learning with mobile technology was primary or elementary school. This is in line with the results of Crompton et al. $(2016,2017)$. There are differences between countries or regions regarding common subjects, 
IADIS International Journal on WWW/Internet

educational levels, and group sizes in outdoor learning with mobile technology. In five of the top seven countries, biology was the most common subject. In Sweden mathematics was most common and in USA natural science was most common. In five of the top seven countries primary or elementary school was the most common educational level. In the UK and Germany secondary school were the most common. In Taiwan, the UK, USA, Germany, and Finland higher education was the second most common educational level. In five of the top seven countries groups of two to three students was the most common. In Taiwan and Singapore, however, individual learning was the most common.

The second research question: "What types of technologies for positioning or navigation, augmentation, and methods for data collection and annotation are used in outdoor learning with mobile technology?" can be answered as follows: Technologies for positioning or navigation were common, reported in 65 of the 87 articles. GPS was the most common technology for positioning or navigation, reported in 46 articles, followed by $Q R$ codes (17), and RFID (7). That positioning or navigation was common is in line with the results of Suárez et al. (2018), who found that location guidance was common in mobile inquiry-based learning. $A R$ was the most common technology for augmenting the outdoor learning environment, reported in 14 articles. The use of AR has also increased in the last two years of the review. Finally, taking photos, reported in 40 articles, followed by taking notes (20), and recording audio (13), were the most common methods for collecting data or making annotations. This is also in line with the results of Suárez et al. (2018), who found that data collection by using these methods were common in mobile inquiry-based learning.

A number of gaps have been identified in this review. First, the most common subject was biology. Future studies on outdoor learning with mobile technology may focus on other subjects further down the list. Second, all of the articles had students from primary or elementary school to higher education. Studies of outdoor learning with mobile technology in pre-kindergarten, kindergarten or pre-school are needed. Third, mobile phones were the most common mobile devices. Tablets were increasingly being used. Studies using smart watches are still lacking. Fourth, few studies used two technologies for positioning or navigation and no articles used three or more. Future studies could support the whole range from small-scale to large-scale positioning and navigation by using two or more technologies, available in mobile phones. Fifth, in many studies students took photos and notes by using mobile devices or other mobile technology. Only ten articles reported that video was used for data collection, and six articles reported that probes were used. More studies could use video or probes for data collection.

This review has a number of limitations. Even though the review method was applied in a thorough way, one limitation is that there may be articles fulfilling the inclusion criteria that were not identified through the database and manual search. Another limitation is that no inter-rater reliability check has been performed. One more limitation is that only articles published in English were included in the review.

\section{REFERENCES}

Almeida, R. R. and Araújo Jr, C. F., 2016. Mobile Learning in Science and Mathematics Teaching: A Systematic Review. Mobile and Blended Learning Innovations for Improved Learning Outcomes. IGI Global.

Anohah, E., et al., 2017. Trends of mobile learning in Computing Education from 2006 to 2014: A systematic review of research publications. In International Journal of Mobile and Blended Learning (IJMBL), Vol. 9, No. 1, pp. 16-33. 
Arrigo, M., et al., 2008. Some Considerations on a Mobile Learning Experience in a Secondary School. World Conference on Mobile and Contextual Learning.

Boticki, I., et al., 2015. Usage of a mobile social learning platform with virtual badges in a primary school. In Computers \& Education, Vol. 86, No., pp. 120-136.

Bursztyn, N., et al., 2017. Assessment of student learning using augmented reality Grand Canyon field trips for mobile smart devices. In Geosphere, Vol. 13, No. 2, pp. 260-268.

Chen, C.-H., et al., 2016. Interaction between Gaming and Multistage Guiding Strategies on Students' Field Trip Mobile Learning Performance and Motivation. In British Journal of Educational Technology, Vol. 47, No. 6, pp. 1032-1050.

Chen, T. S., et al., 2011. A study of learners' attitudes using TAM in a context-aware mobile learning environment. In International Journal of Mobile Learning and Organisation, Vol. 5, No. 2, pp. 144-158.

Chen, Y.-S., et al., 2005. Realizing Outdoor Independent Learning with a Butterfly-Watching Mobile Learning System. In Journal of Educational Computing Research, Vol. 33, No. 4, pp. 395-417.

Chien, Y. C., et al., 2019. Enhancing students' botanical learning by using augmented reality. In Universal Access in the Information Society, Vol. 18, No. 2, pp. 231-241.

Chin, K.-Y., et al., 2019. Effects of an augmented reality-based mobile system on students' learning achievements and motivation for a liberal arts course. In Interactive Learning Environments, Vol. 27, No. 7, pp. 927-941.

Chin, K. Y., et al., 2015. Impact on Student Motivation by Using a QR-Based U-Learning Material Production System to Create Authentic Learning Experiences. In IEEE Transactions on Learning Technologies, Vol. 8, No. 4, pp. 367-382.

Cook, J., 2010. Mobile Phones as Mediating Tools within Augmented Contexts for Development. In International Journal of Mobile and Blended Learning (IJMBL), Vol. 2, No. 3, pp. 1-12.

Costabile, M. F., et al., 2008. Explore! Possibilities and challenges of mobile learning. Conference on Human Factors in Computing Systems - Proceedings, pp. 145-154.

Crompton, H., et al., 2017. The use of mobile learning in PK-12 education: A systematic review. In Computers and Education, Vol. 110, No., pp. 51-63.

Crompton, H., et al., 2016. The Use of Mobile Learning in Science: A Systematic Review. In Journal of Science Education and Technology, Vol. 25, No. 2, pp. 149-160.

Daher, W., 2017. Student Voice in the Mobile Phone Environment: A Grounded Theory Approach. In International Journal of Mobile and Blended Learning (IJMBL), Vol. 9, No. 3, pp. 12-23.

De Crom, N. and De Jager, A., 2006. M-eco-learn: the evolution from paper to pda in ecotourism field work. IADIS International Conference Mobile Learning 2006.

Dugstad Wake, J. and Wasson, B., 2011. Supporting creativity in teaching and learning of history through small-group production of mobile, location-based games. World Conference on Mobile and Contextual Learning.

Edmonds, R. and Smith, S., 2017. From playing to designing: Enhancing educational experiences with location-based mobile learning games. In Australasian Journal of Educational Technology, Vol. 33, No. 6, pp. 41-53.

Efstathiou, I., et al., 2018. An inquiry-based augmented reality mobile learning approach to fostering primary school students' historical reasoning in non-formal settings. In Interactive Learning Environments, Vol. 26, No. 1, pp. 22-41.

Eliasson, J., et al., 2011. Mobile Devices as Support Rather than Distraction for Mobile Learners: Evaluating Guidelines for Design. In International Journal of Mobile and Blended Learning (IJMBL), Vol. 3, No. 2, pp. 1-15. 
IADIS International Journal on WWW/Internet

Elyakim, N., et al., 2019. Perceptions of Transactional Distance in Blended Learning Using Location-Based Mobile Devices. In Journal of Educational Computing Research, Vol. 57, No. 1, pp. 131-169.

Facer, K., et al., 2004. Savannah: mobile gaming and learning? In Journal of Computer Assisted Learning, Vol. 20, No. 6, pp. 399-409.

Fiennes, C., et al., 2015. The existing evidence-base about the effectiveness of outdoor learning. In Institute of Outdoor Learning: London, UK, Vol., No., pp.

Folkestad, J. and O'shea, P., 2011. An Analysis of Engagement in a Combination Indoor/Outdoor Augmented Reality Educational Game. In Journal on School Educational Technology, Vol. 7, No. 1, pp. 30-37.

Frohberg, D., et al., 2009. Mobile Learning projects - a critical analysis of the state of the art: Original article. In Journal of Computer Assisted Learning, Vol. 25, No. 4, pp. 307-331.

Hooper, G., et al., 2008. Does it matter who is holding the pda in a mobile learning experience? IADIS International Conference Mobile Learning 2008.

Hsiao, H.-S., et al., 2010. Location Based Services for Outdoor Ecological Learning System: Design and Implementation. In Educational Technology \& Society, Vol. 13, No. 4, pp. 98-111.

Huang, T.-C., et al., 2019. Do Learning Styles Matter? Motivating Learners in an Augmented Geopark. In Educational Technology \& Society, Vol. 22, No. 1, pp. 70-81.

Huang, Y. M., et al., 2010. Effectiveness of a Mobile Plant Learning System in a science curriculum in Taiwanese elementary education. In Computers and Education, Vol. 54, No. 1, pp. 47-58.

Huizenga, J., et al., 2009. Mobile game-based learning in secondary education: engagement, motivation and learning in a mobile city game. In Journal of Computer Assisted Learning, Vol. 25, No. 4, pp. 332-344.

Hung, P.-H., et al., 2013. Seamless Connection between Learning and Assessment--Applying Progressive Learning Tasks in Mobile Ecology Inquiry. In Educational Technology \& Society, Vol. 16, No. 1, pp. 194-205.

Hwang, G.-J. and Chang, S.-C., 2016. Effects of a peer competition-based mobile learning approach on students' affective domain exhibition in social studies courses. In British Journal of Educational Technology, Vol. 47, No. 6, pp. 1217-1231.

Hwang, G.-J., et al., 2018. Effects of integrating an active learning-promoting mechanism into location-based real-world learning environments on students' learning performances and behaviors. In Educational Technology Research and Development, Vol. 66, No. 2, pp. 451-474.

Hwang, G.-J., et al., 2016. Effects of an Augmented Reality-Based Educational Game on Students' Learning Achievements and Attitudes in Real-World Observations. In Interactive Learning Environments, Vol. 24, No. 8, pp. 1895-1906.

Jong, M. S.-Y., et al., 2018. Gamifying and Mobilising Social Enquiry-Based Learning in Authentic Outdoor Environments. In Educational Technology \& Society, Vol. 21, No. 4, pp. 277-292.

Jong, M. S. Y., et al., 2012. An integrated GPS-supported outdoor exploratory educational system - EagleEye. Proceedings of the 20th International Conference on Computers in Education, ICCE 2012, pp. 338-345.

Kacoroski, J., et al., 2016. Children's Use of iPads in Outdoor Environmental Education Programs. In Applied Environmental Education and Communication, Vol. 15, No. 4, pp. 301-311.

Kamarainen, A. M., et al., 2018. Prompting connections between content and context: Blending immersive virtual environments and augmented reality for environmental science learning. Communications in Computer and Information Science.

Kapoun, P. and Kapounová, J., 2016. Instruction outside the classroom: Mobile, or ubiquitous learning? Proceedings of the European Conference on e-Learning, ECEL, pp. 340-349. 
Kissi, L. and Dreesmann, D., 2018. Plant visibility through mobile learning? Implementation and evaluation of an interactive Flower Hunt in a botanic garden. In Journal of Biological Education, Vol. 52, No. 4, pp. 344-363.

Kuikkaniemi, K., et al., 2014. Lost lab of professor millennium: Creating a pervasive adventure with augmented reality-based guidance. ACM International Conference Proceeding Series, pp.

Kukulska-Hulme, A. and Viberg, O., 2018. Mobile collaborative language learning: State of the art. In British Journal of Educational Technology, Vol. 49, No. 2, pp. 207-218.

Kurniawan, I. S., et al., 2017. How can Smartphone-Based Internet Data Support Animal Ecology Fieldtrip? Journal of Physics: Conference Series, pp.

Kurti, A., et al., 2008. Bridging outdoors and indoors educational activities in schools with the support of mobile and positioning technologies. In IJMLO, Vol. 2, No. 2, pp. 166-186.

Kärki, T., et al., 2018. Meaningful learning with mobile devices: pre-service class teachers' experiences of mobile learning in the outdoors. In Technology, Pedagogy and Education, Vol. 27, No. 2, pp. 251-263.

Lai, A.-F., et al., 2015. Developing a Mobile Learning Management System for Outdoors Nature Science Activities Based on 5E Learning Cycle. IADIS International Conference e-Learning 2015 (part of MCCSIS 2015). International Association for Development of the Information Society.

Lai, C. H., et al., 2014. Exploration of tensions in a mobile-technology supported fieldtrip: An activity theory perspective. In International Journal of Distance Education Technologies, Vol. 12, No. 2, pp. 104-117.

Lai, C. H., et al., 2013. Learners' acceptance of mobile technology supported collaborative learning. In International Journal of Mobile Learning and Organisation, Vol. 7, No. 3-4, pp. 277-291.

Laru, J., et al., 2012. Supporting collaborative inquiry during a biology field trip with mobile peer-to-peer tools for learning: A case study with K-12 learners. In Interactive Learning Environments, Vol. 20, No. 2, pp. 103-117.

Lee, W. S. and Chang, C. Y., 2014. The application of QR codes in outdoor education activities: Practice and discussion. Workshop Proceedings of the 22nd International Conference on Computers in Education, ICCE 2014, pp. 756-765.

Lemcke, S., et al., 2015. RouteMe: A multilevel pervasive game on mobile ad hoc routing. In Personal and Ubiquitous Computing, Vol. 19, No. 3, pp. 537-549.

Liao, A. Y. H., et al., 2012. A cloud-based ubiquitous learning system using flow learning model - A case study of the instruction on nature and life sciences of elementary school. Workshop Proceedings of the 20th International Conference on Computers in Education, ICCE 2012, pp. 388-396.

Liberati, A., et al., 2009. The PRISMA statement for reporting systematic reviews and meta-analyses of studies that evaluate health care interventions: Explanation and elaboration. In PLoS Medicine, Vol. 6, No. 7, pp.

Lima, F., et al., 2012. A geo-referenced multisensory graphical editor for elementary education. IADIS International Conference e-Learning 2012 (part of MCCSIS 2012).

Lin, Y. T., et al., 2018. Development of a SoLoMo game-based application for supporting local cultural learning in Taiwan. In Educational Technology and Society, Vol. 21, No. 4, pp. 115-128.

Liu, T.-Y., 2009. A context-aware ubiquitous learning environment for language listening and speaking. In Journal of Computer Assisted Learning, Vol. 25, No. 6, pp. 515-527.

Liu, T.-Y., et al., 2009. Outdoor Natural Science Learning with an RFID-Supported Immersive Ubiquitous Learning Environment. In Educational Technology \& Society, Vol. 12, No. 4, pp. 161-175.

Lohr, M., 2009. Mobile learning by the example of the Carnuntum scenario. International Conference on Intelligent Networking and Collaborative Systems, INCoS 2009, pp. 46-52.

Marçal, E., et al., 2017. Development and Evaluation of a Model-Driven System to Support Mobile Learning in Field Trips. In J. UCS, Vol. 23, No. 12, pp. 1147-1171. 
IADIS International Journal on WWW/Internet

MarçAl, E., et al., 2015. A mobile learning system to enhance field trips in geology. Proceedings Frontiers in Education Conference, FIE, pp.

Marty, P. F., et al., 2013. Scientific Inquiry, Digital Literacy, and Mobile Computing in Informal Learning Environments. Learning, Media and Technology.

Mcgreen, N. and Arnedillo Sánchez, I., 2005. Mapping challenge: a case study in the use of mobile phones in collaborative, contextual learning. IADIS International Conference Mobile Learning 2005.

Meishar-Tal, H. and Gross, M., 2014. Teaching sustainability via smartphone-enhanced experiential learning in a botanical garden. In International Journal of Interactive Mobile Technologies, Vol. 8, No. 1, pp. 10-15.

Melzer, A., et al., 2006. Using the moles and mini moles software system to bridge the gap between indoor and outdoor learning. In IADIS International Journal on WWW/Internet, Vol., No., pp.

Mettis, K. and Väljataga, T., 2018. Get out! - Helping teachers orchestrate outdoor game-based learning activities. Proceedings of the 15th International Conference on Cognition and Exploratory Learning in the Digital Age, CELDA 2018, pp. 3-10.

Muñoz-Cristóbal, J. A., et al., 2015. Supporting Teacher Orchestration in Ubiquitous Learning Environments: A Study in Primary Education. In IEEE Transactions on Learning Technologies, Vol. 8, No. 1, pp. 83-97.

Nikou, S. A. and Economides, A. A., 2016. An outdoor mobile-based assessment activity: Measuring students' motivation and acceptance. In International Journal of Interactive Mobile Technologies, Vol. 10, No. 4, pp. 11-17.

Nouri, J. and Cerratto-Pargman, T., 2015. Characterizing Learning Mediated by Mobile Technologies: A Cultural-Historical Activity Theoretical Analysis. In IEEE Transactions on Learning Technologies, Vol. 8, No. 4, pp. 357-366.

Nouri, J., et al., 2011. Exploring the Challenges of Supporting Collaborative Mobile Learning. In International Journal of Mobile and Blended Learning (IJMBL), Vol. 3, No. 4, pp. 54-69.

Ogata, H., et al., 2008. Supporting Classroom Activities with the BSUL System. In Educational Technology \& Society, Vol. 11, No. 1, pp. 1-16.

Osawa, N., et al., 2007. Outdoor Education Support System with Location Awareness Using RFID and Symbology Tags. In Journal of Educational Multimedia and Hypermedia, Vol. 16, No. 4, pp. 411-428.

Peng, A. and Sollervall, H., 2014. Primary School Students' Spatial Orientation Strategies in an Outdoor Learning Activity Supported by Mobile Technologies. In International Journal of Education in Mathematics, Science and Technology, Vol. 2, No. 4, pp. 246-256.

Pfeiffer, V. D. I., et al., 2009. Situated Learning in the Mobile Age: Mobile Devices on a Field Trip to the Sea. In ALT-J: Research in Learning Technology, Vol. 17, No. 3, pp. 187-199.

Pombo, L. and Marques, M. M., 2019. Improving students' learning with a mobile augmented reality approach - the EduPARK game. In Interactive Technology and Smart Education, Vol. 16, No. 4, pp. 392-406.

Rickinson, M., et al., 2004. A review of research on outdoor learning, Field Studies Council.

Rikala, J., 2015. Enhancing Children's Outdoor Learning Experiences with a Mobile Application. In Journal of Educational Multimedia and Hypermedia, Vol. 24, No. 2, pp. 139-159.

Rogers, Y., et al., 2004. Ambient wood: Designing new forms of digital augmentation for learning outdoors. Proceedings of the 2004 Conference on Interaction Design and Children: Building a Community, IDC 2004, pp. 3-10.

Rose, M. A., et al., 2014. Mobile Learning: Geocaching to Learn about Energy Systems. In Technology and Engineering Teacher, Vol. 74, No. 1, pp. 17-23. 
Schaal, S., et al., 2018. Game-Related Enjoyment or Personal Pre-Requisites--Which Is the Crucial Factor When Using Geogames to Encourage Adolescents to Value Local Biodiversity. In International Journal of Science Education, Part B: Communication and Public Engagement, Vol. 8, No. 3, pp. 213-226.

Schwabe, G. and Göth, C., 2005. Mobile learning with a mobile game: design and motivational effects. In Journal of Computer Assisted Learning, Vol. 21, No. 3, pp. 204-216.

Sharples, M., et al., 2012. Zapp: Learning about the Distant Landscape. World Conference on Mobile and Contextual Learning.

Sharples, M., et al., 2007. A Theory of Learning for the Mobile Age. In: Andrews, R. \& Haythornthwaite, C. A. (eds.) The SAGE handbook of e-learning research. Thousand Oaks, Calif.: SAGE Publications.

Shih, J.-L., et al., 2009. Analysis of student attitudes for participating in a context-aware ubiquitous learning activity with repertory grid approach. IADIS International Conference Mobile Learning 2009.

Sollervall, H., et al., 2012. Outdoor activities for the learning of mathematics: Designing with mobile technologies for transitions across learning contexts. 2012 IEEE Seventh International Conference on Wireless, Mobile and Ubiquitous Technology in Education. IEEE.

Song, Y., et al., 2012. Fostering personalized learning in science inquiry supported by mobile technologies. In Educational Technology Research and Development, Vol. 60, No. 4, pp. 679-701.

Su, C. H. and Cheng, C. H., 2015. A Mobile Gamification Learning System for Improving the Learning Motivation and Achievements. In Journal of Computer Assisted Learning, Vol. 31, No. 3, pp. 268-286.

Suárez, Á., et al., 2018. A review of the types of mobile activities in mobile inquiry-based learning. In Computers \& Education, Vol. 118, No., pp. 38-55.

Tan, E., et al., 2018. Mobile Inquiry-based Learning: Relationship among levels of inquiry, learners' autonomy and environmental interaction. In: Parsons, D., Power, R., Palalas, A., Hambrock, H. \& Maccallum, K. (eds.) World Conference on Mobile and Contextual Learning 2018. Concordia University Chicago, Chicago, IL, USA.

Tan, E. and So, H. J., 2013. Students' capacity for autonomous learning in an unstructured learning space on a mobile learning trail. Computer-Supported Collaborative Learning Conference, CSCL, pp. 169-172.

Tan, N., et al., 2007. Handheld computers as cognitive tools: An environmental learning project in Singapore. 15th International Conference on Computers in Education: Supporting Learning Flow through Integrative Technologies, ICCE 2007, pp. 377-384.

Tarng, W. and Ou, K.-L., 2012. A study of campus butterfly ecology learning system based on augmented reality and mobile learning. 2012 IEEE Seventh International Conference on Wireless, Mobile and Ubiquitous Technology in Education, pp. 62-66.

Tarumi, H., et al., 2008. KEI-Time Traveler: Visiting a past world with mobile phones to enhance learning motivation. Proceedings of the 7th International Conference on Interaction Design and Children, IDC 2008, pp. 161-164.

Wingkvist, A. and Ericsson, M., 2011. A Survey of Research Methods and Purposes in Mobile Learning. In International Journal of Mobile and Blended Learning (IJMBL), Vol. 3, No. 1, pp. 1-17.

Winter, M. and Pemberton, L., 2011. Unearthing Invisible Buildings: Device Focus and Device Sharing in a Collaborative Mobile Learning Activity. In International Journal of Mobile and Blended Learning (IJMBL), Vol. 3, No. 4, pp. 1-18.

Wong, L.-H. and Looi, C.-K., 2010. Vocabulary learning by mobile-assisted authentic content creation and social meaning-making: two case studies. In Journal of Computer Assisted Learning, Vol. 26, No. 5 , pp. 421-433.

Woodgate, D., et al., 2008. Mobile Learning in Context: School Science Data Collection as Legitimate Peripheral Participation? World Conference on Mobile and Contextual Learning. 
IADIS International Journal on WWW/Internet

$\mathrm{Wu}, \mathrm{S}$., et al., 2010. Learning historical and cultural contents via mobile treasure hunting in five-harbor district of Tainan, Taiwan. 6th IEEE International Conference on Wireless, Mobile and Ubiquitous Technologies in Education, WMUTE 2010: Mobile Social Media for Learning and Education in Formal and Informal Settings, pp. 213-215.

Young, S. S. C., et al., 2008. Uses of the Across Mobile Platform Learning system (AMPLe) in supporting outdoor mobile learning scenarios. Proceedings - 2008 the 1st IEEE International Conference on Ubi-Media Computing and Workshops, U-Media2008, pp. 290-295.

Zacharia, Z. C., et al., 2016. The use of mobile devices as means of data collection in supporting elementary school students' conceptual understanding about plants. In International Journal of Science Education, Vol. 38, No. 4, pp. 596-620.

\section{APPENDIX A: EXTRACTED DATA}

\begin{tabular}{|c|c|c|c|c|c|c|c|c|c|c|c|c|c|c|c|c|c|c|}
\hline 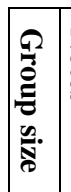 & $\mid \begin{array}{l}z \\
\bar{a} \\
\vec{*}\end{array}$ & 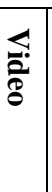 & 胥 & $\overline{\bar{z}}$ & $\frac{\pi}{0}$ & 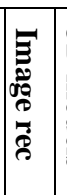 & 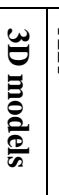 & $\vec{Z}$ & 远 & 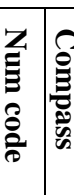 & 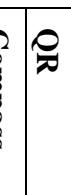 & 齐 & $\frac{2}{80}$ & ) & 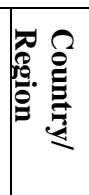 & 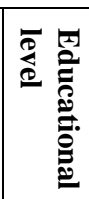 & 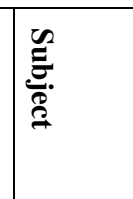 & 莺 \\
\hline $\begin{array}{l}N \\
\vec{O} \\
+\end{array}$ & $x$ & & . & $x$ & & & & & & & & & $\star$ & $\begin{array}{l}3 \\
\frac{3}{0} \\
\frac{0}{0} \\
0 \\
\frac{0}{0} \\
0 \\
0\end{array}$ & 芠 & 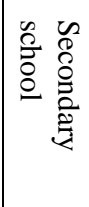 & 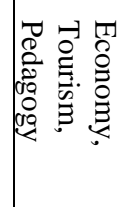 & 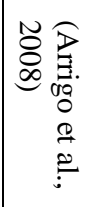 \\
\hline- & $\star$ & $\rtimes$ & $\star$ & $x$ & & & & & & & & & $\times$ & 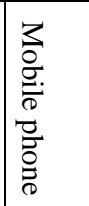 & 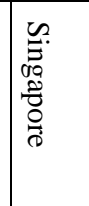 & 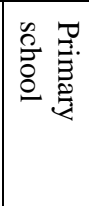 & 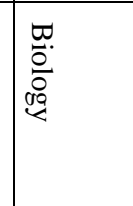 & 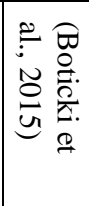 \\
\hline- & & & & & & & & & & & & & $\times$ & 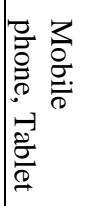 & $\begin{array}{l}\mathscr{5} \\
D \\
D\end{array}$ & 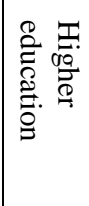 & 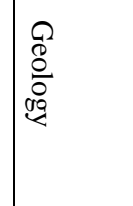 & 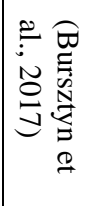 \\
\hline- & & & & & & & & & & & $\star$ & & & $\overrightarrow{\ddot{\tilde{\sigma}}}$ & 島. & 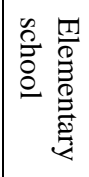 & 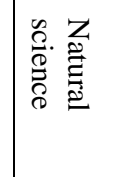 & 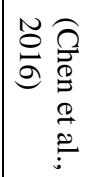 \\
\hline- & & & & & & & & & & & & $x$ & & $\underset{D}{\vec{D}}$ & 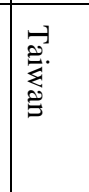 & 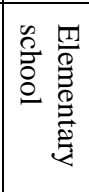 & 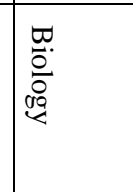 & 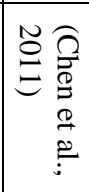 \\
\hline
\end{tabular}


OUTDOOR LEARNING WITH MOBILE TECHNOLOGY: A SYSTEMATIC REVIEW

\begin{tabular}{|c|c|c|c|c|c|c|c|c|c|c|c|c|c|c|c|c|}
\hline 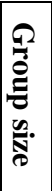 & 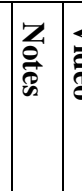 & 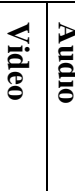 & $\frac{\pi}{0}$ & $\frac{\pi}{2}$ & 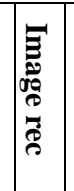 & 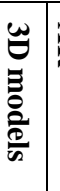 & & 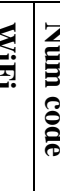 & 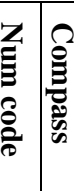 & \% & 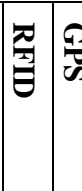 & : & 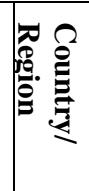 & 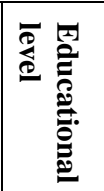 & 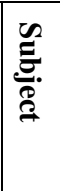 & 趇 \\
\hline N & $x$ & & $x$ & 4 & $x$ & & $x$ & & & & & $\underset{D}{\vec{D}}$ & 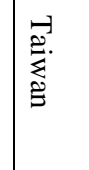 & 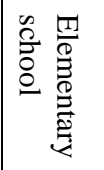 & 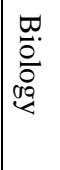 & 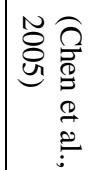 \\
\hline- & & & & & & $*$ & $\star$ & & & & & $\begin{array}{l}\overrightarrow{\tilde{\sigma}} \\
\vec{\sigma}\end{array}$ & 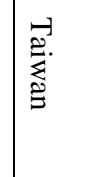 & 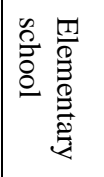 & 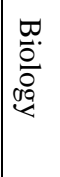 & 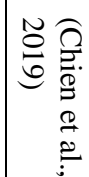 \\
\hline N & & & & & & $\times$ & $x$ & & & & & $\begin{array}{l}3 \\
0 \\
\frac{0}{0} \\
\frac{0}{0} \\
\frac{0}{0} \\
\frac{0}{0}\end{array}$ & 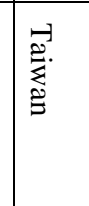 & 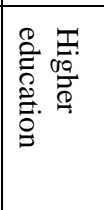 & 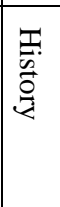 & 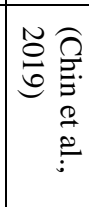 \\
\hline- & & & & & & & & & & 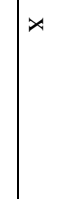 & & $\begin{array}{l}3 \\
\frac{3}{0} \\
\frac{0}{0} \\
0 \\
\frac{0}{0} \\
0 \\
0 \\
0\end{array}$ & 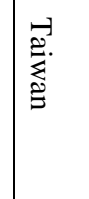 & 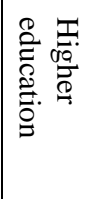 & 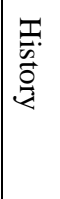 & 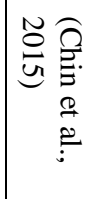 \\
\hline$N$ & & $\star$ & & & & $\star$ & & & & & * & 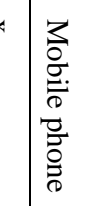 & 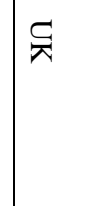 & 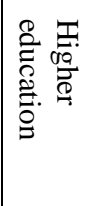 & 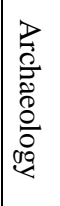 & 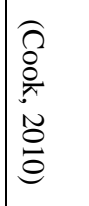 \\
\hline $\begin{array}{l}\omega \\
\overrightarrow{0} \\
u\end{array}$ & & & & & & $x$ & & & $x$ & & & 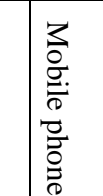 & $\underset{\vec{\nabla}}{\vec{E}}$ & 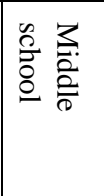 & 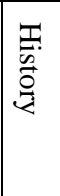 & 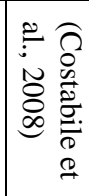 \\
\hline-1 & & & & & & & & & & & & $\begin{array}{l}3 \\
0 \\
\frac{0}{0} \\
\frac{0}{0} \\
\frac{0}{0} \\
\frac{0}{0} \\
\frac{0}{0}\end{array}$ & 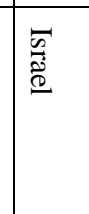 & 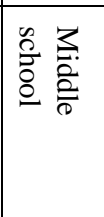 & 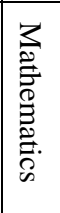 & 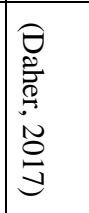 \\
\hline
\end{tabular}


IADIS International Journal on WWW/Internet

\begin{tabular}{|c|c|c|c|c|c|c|c|c|c|c|c|c|c|c|c|c|c|c|}
\hline 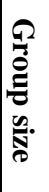 & 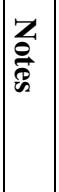 & 4 & : & 훌 & $\frac{\pi}{0}$ & 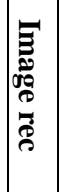 & 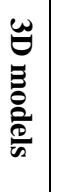 & $\vec{d}$ & 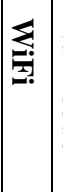 & 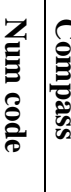 & 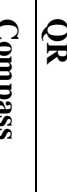 & 줍 & $\frac{\Omega}{6}$ & 迸 & 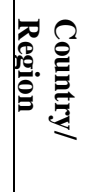 & 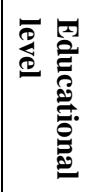 & 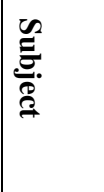 & | \\
\hline- & $x$ & & & $x$ & & & & & & & & & & $\underset{D}{\vec{D}}$ & 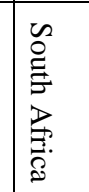 & 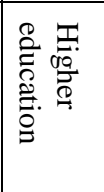 & 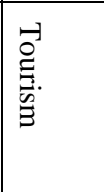 & 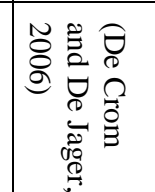 \\
\hline $\begin{array}{l}\omega \\
0 \\
\phi \\
+\end{array}$ & & & & $x$ & & & & & & & & & $x$ & $\begin{array}{l}\frac{3}{2} \\
\frac{0}{5} \\
\frac{0}{0} \\
\frac{0}{0} \\
0 \\
0\end{array}$ & 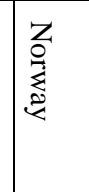 & 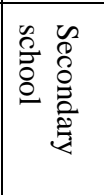 & 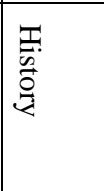 & 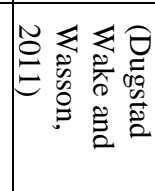 \\
\hline ur & 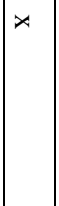 & & & $x$ & & & & & & & & & $x$ & 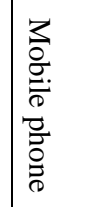 & 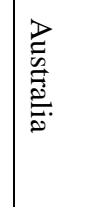 & 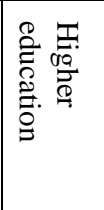 & 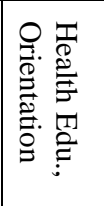 & 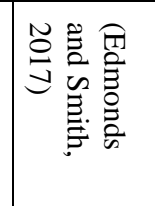 \\
\hline $\begin{array}{l}N \\
\overrightarrow{0} \\
\omega\end{array}$ & $x$ & & & $x$ & & & & $\star$ & & & & & $x$ & $\stackrel{\overrightarrow{\tilde{\sigma}}}{\stackrel{\oplus}{Q}}$ & 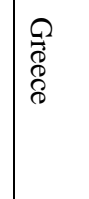 & 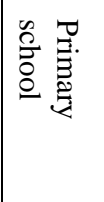 & 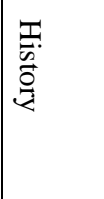 & 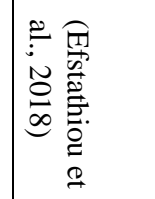 \\
\hline$\omega$ & & & & & & & & & & & & & $\star$ & $\begin{array}{l}3 \\
0 \\
\frac{0}{0} \\
\frac{0}{0} \\
\frac{0}{0} \\
0 \\
0\end{array}$ & 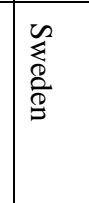 & 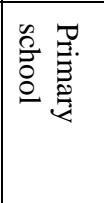 & 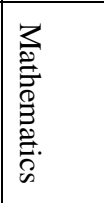 & 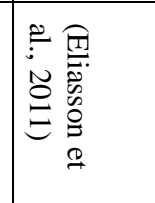 \\
\hline $\begin{array}{l}\vec{t} \\
\overrightarrow{0} \\
u\end{array}$ & & $x$ & & $\star$ & & & & & & & & & $x$ & $\begin{array}{l}\overrightarrow{\tilde{\sigma}} \\
\vec{\Phi}\end{array}$ & $\begin{array}{l}\bar{n} \\
\tilde{0} \\
0\end{array}$ & 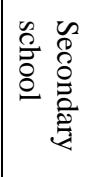 & 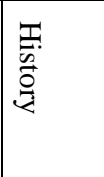 & 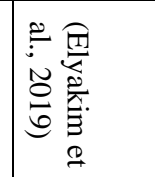 \\
\hline ur & & & & & & & & & & & & & $x$ & $\underset{D}{\vec{D}}$ & $\stackrel{\subseteq}{\pi}$ & 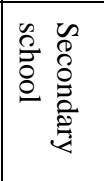 & 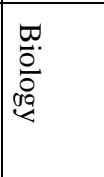 & 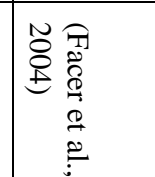 \\
\hline
\end{tabular}


OUTDOOR LEARNING WITH MOBILE TECHNOLOGY: A SYSTEMATIC REVIEW

\begin{tabular}{|c|c|c|c|c|c|c|c|c|c|c|c|c|c|c|c|c|c|}
\hline 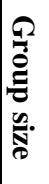 & 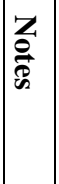 & 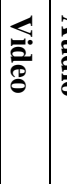 & 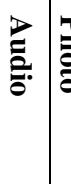 & $\overline{\bar{t}}$ & 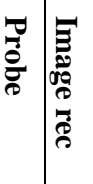 & 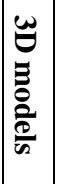 & & 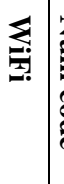 & 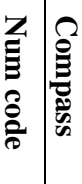 & 유 & 尩 & $\frac{\Omega}{2}$ & 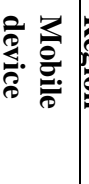 & 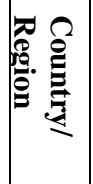 & 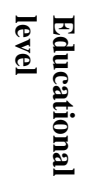 & 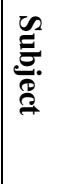 & 莺 \\
\hline N & & & & & & & $x$ & & & & & $\times$ & $\begin{array}{l}3 \\
\frac{3}{0} \\
\frac{0}{0} \\
\frac{0}{0} \\
\frac{0}{0} \\
0\end{array}$ & $\begin{array}{c}c \\
\mathbb{D} \\
>\end{array}$ & 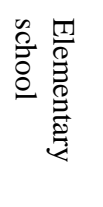 & 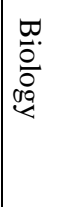 & 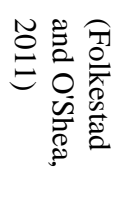 \\
\hline N & $\star$ & & $\star$ & & & & & $\star$ & & & & $\times$ & $\underset{D}{\vec{D}}$ & $\stackrel{\nwarrow}{\nwarrow}$ & 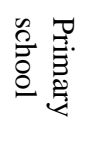 & 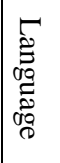 & 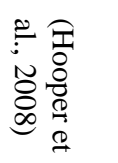 \\
\hline- & 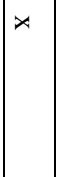 & & & $x$ & & & & & & & & $\times$ & $\vec{D}$ & 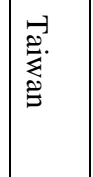 & 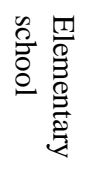 & 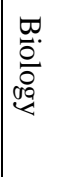 & 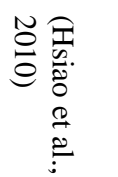 \\
\hline- & & & & & & $x$ & $x$ & & & & $\star x$ & & $\stackrel{\overrightarrow{\tilde{\sigma}}}{\stackrel{\leftrightarrow}{\sigma}}$ & 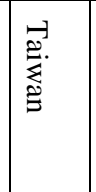 & 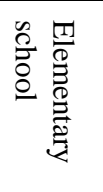 & 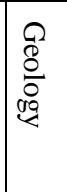 & 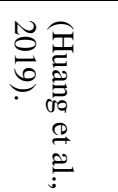 \\
\hline D & & & & $x$ & 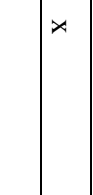 & & & & & & & $\times$ & $\underset{D}{\vec{D}}$ & . & 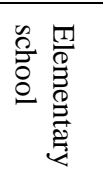 & 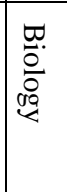 & 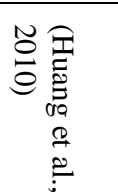 \\
\hline $\begin{array}{l}N \\
\overrightarrow{0} \\
\omega\end{array}$ & & $x$ & & $x$ & & & & & & & & $\begin{array}{l}x \\
0 \\
0 \\
0\end{array}$ & $\begin{array}{l}3 \\
0 \\
\frac{0}{0} \\
\overline{0} \\
\frac{\overrightarrow{0}}{0} \\
\frac{0}{0}\end{array}$ & 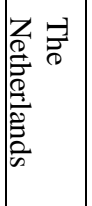 & 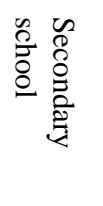 & 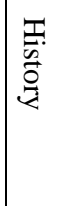 & 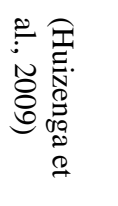 \\
\hline- & 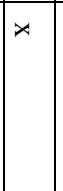 & & & $\rtimes$ & & & & & & & & & $\underset{D}{\vec{D}}$ & 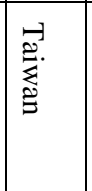 & 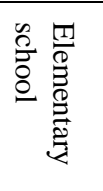 & 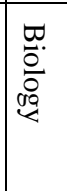 & 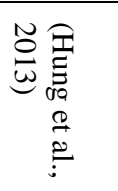 \\
\hline
\end{tabular}


IADIS International Journal on WWW/Internet

\begin{tabular}{|c|c|c|c|c|c|c|c|c|c|c|c|c|c|c|c|c|c|}
\hline 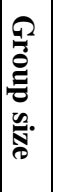 & 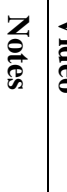 & 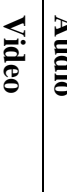 & 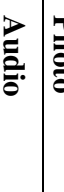 & $\overline{\mathrm{z}}$ & 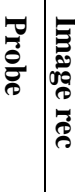 & 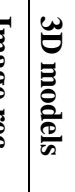 & $\mathbb{d}$ & 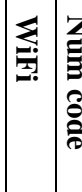 & 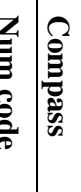 & O & $\underset{\mathbf{z}}{\boldsymbol{\pi}}$ & \begin{tabular}{l}
$\Omega$ \\
\hdashline \\
\hdashline
\end{tabular} & 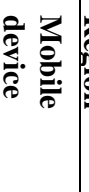 & 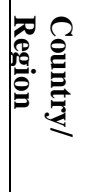 & 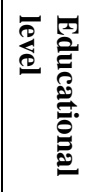 & 足 & 胥 \\
\hline- & & & & & & & & & & $x$ & & & $\overrightarrow{\ddot{\ddot{\sigma}}}$ & 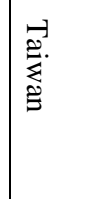 & 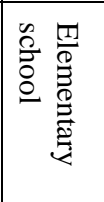 & 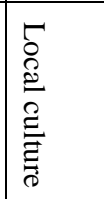 & 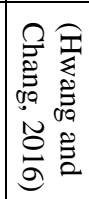 \\
\hline- & & & & & & & 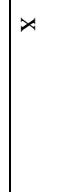 & & & & & & $\overrightarrow{\ddot{\sigma}}$ & 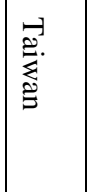 & 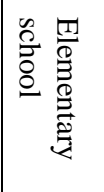 & 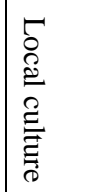 & 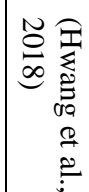 \\
\hline- & & & & & & & $x$ & & & $x$ & & & $\begin{array}{l}3 \\
0 \\
\frac{0}{0} \\
\frac{0}{0} \\
\frac{0}{0} \\
0 \\
0\end{array}$ & 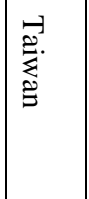 & 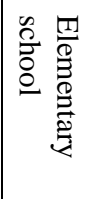 & 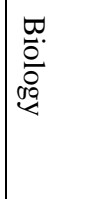 & 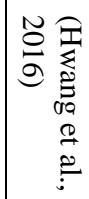 \\
\hline $\begin{array}{l}\vec{t} \\
\overrightarrow{0} \\
u \\
\text { un }\end{array}$ & & & & & & & & & & & & $\times$ & $\underset{\stackrel{\vec{\sigma}}{\sigma}}{\stackrel{\vec{\sigma}}{\sigma}}$ & 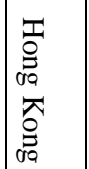 & 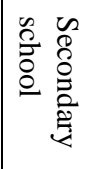 & 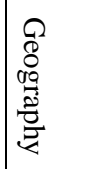 & 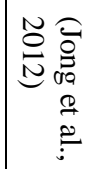 \\
\hline - & & $\star>$ & $\star x$ & $\star$ & & & & & & & & $\star$ & $\underset{\vec{\sigma}}{\vec{\sigma}}$ & 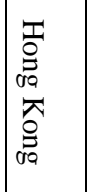 & 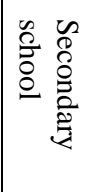 & 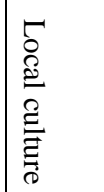 & 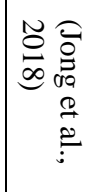 \\
\hline $\overrightarrow{\overrightarrow{0}}$ & & & & & & & & & & & & & $\frac{\overrightarrow{\tilde{\sigma}}}{\Phi}$ & $\begin{array}{l}\tilde{G} \\
\text { D } \\
>\end{array}$ & 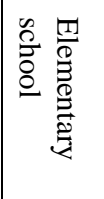 & 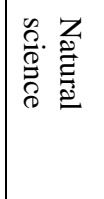 & 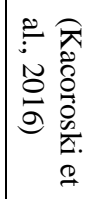 \\
\hline $\begin{array}{l}N \\
\overrightarrow{0} \\
\omega\end{array}$ & $x$ & & & $\star$ & $x$ & $x$ & $x$ & & & & & $x$ & $\begin{array}{l}\frac{3}{0} \\
\frac{0}{0} \\
\frac{0}{0} \\
\frac{0}{0} \\
\frac{0}{0}\end{array}$ & $\begin{array}{l}\check{5} \\
5 \\
>\end{array}$ & 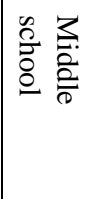 & 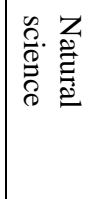 & 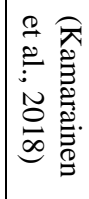 \\
\hline
\end{tabular}


OUTDOOR LEARNING WITH MOBILE TECHNOLOGY: A SYSTEMATIC REVIEW

\begin{tabular}{|c|c|c|c|c|c|c|c|c|c|c|c|c|c|c|c|c|c|c|}
\hline 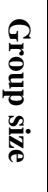 & $\frac{z}{2}$ & 4 & : & 훌 & ְ̋ & 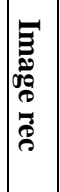 & 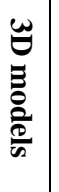 & $\mathbb{d}$ & 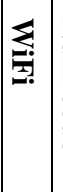 & 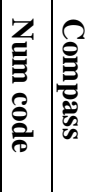 & $\underbrace{2}_{0}$ & 줄 & 8 & 产 & 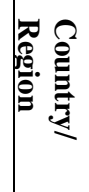 & 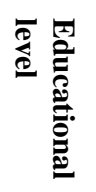 & 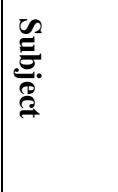 & 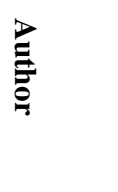 \\
\hline$N$ & & & & & & & & & & & & & $x$ & $\overrightarrow{\vec{\sigma}}$ & 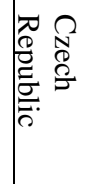 & 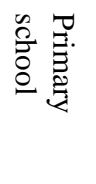 & 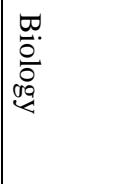 & 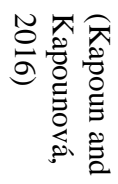 \\
\hline $\begin{array}{l}N \\
\tilde{D} \\
\omega\end{array}$ & & & & $x$ & & & & & & & $\star$ & & $x$ & $\begin{array}{l}\overrightarrow{\mathscr{\sigma}} \\
\frac{\tilde{\sigma}}{\sigma}\end{array}$ & 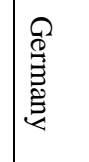 & 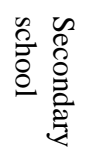 & 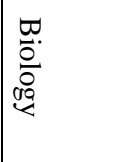 & 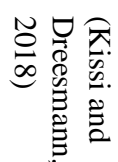 \\
\hline $\begin{array}{l}\omega \\
\overrightarrow{0} \\
+\end{array}$ & & & & 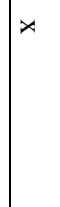 & & & & $x$ & & & & $\star$ & 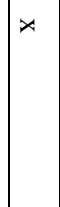 & $\begin{array}{l}3 \\
\frac{3}{0} \\
\frac{0}{0} \\
0 \\
\frac{0}{0} \\
0 \\
0\end{array}$ & 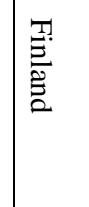 & 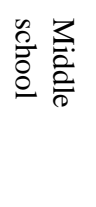 & $\bar{\Omega}$ & 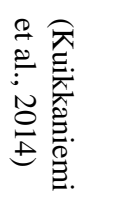 \\
\hline 6 & & & & & & & & & & & & & & 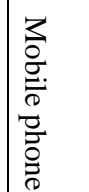 & 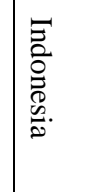 & 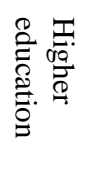 & 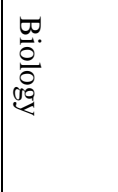 & 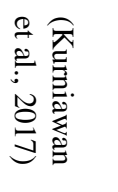 \\
\hline $\begin{array}{l}w \\
w \\
\dot{v} \\
u\end{array}$ & & $x$ & 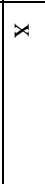 & $x$ & & & & & & & $x$ & & $x$ & 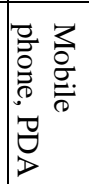 & $\begin{array}{l}n \\
\tilde{k} \\
0 \\
\hat{0} \\
\Xi \\
\end{array}$ & 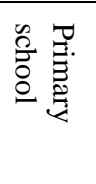 & 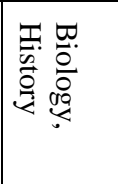 & 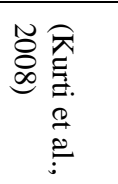 \\
\hline $\begin{array}{l}n \\
\overrightarrow{0} \\
a\end{array}$ & & & & $\star$ & & & & & & & & & $x$ & 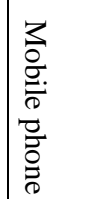 & 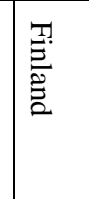 & 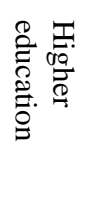 & 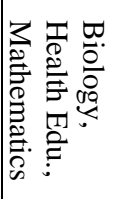 & 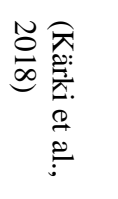 \\
\hline- & $\star x$ & & & $\star$ & & & & & & & $x$ & & & $\stackrel{\overrightarrow{\tilde{\sigma}}}{\stackrel{\vec{\sigma}}{\sigma}}$ & 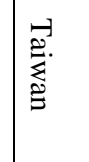 & 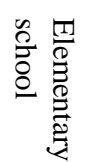 & 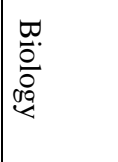 & 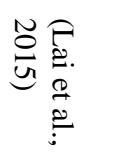 \\
\hline
\end{tabular}


IADIS International Journal on WWW/Internet

\begin{tabular}{|c|c|c|c|c|c|c|c|c|c|c|c|c|c|c|}
\hline 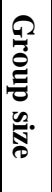 & 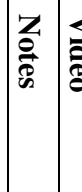 & : & $\frac{\pi}{\bar{\sigma}}$ & 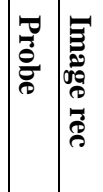 & 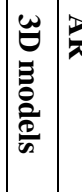 & 记 & 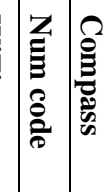 & 유 & 줄 & 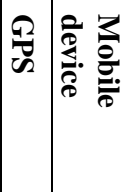 & 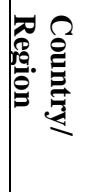 & 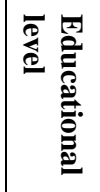 & 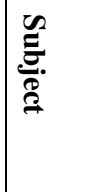 & 胥 \\
\hline- & 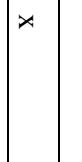 & $\star$ & $x$ & & & & & & & $\underset{D}{\vec{D}}$ & ت. & 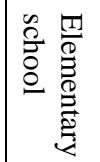 & 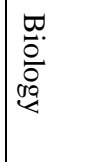 & 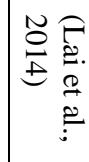 \\
\hline ur & & & & & & & & & & $\underset{D}{\vec{D}}$ & ث. & 然 & 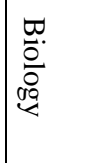 & 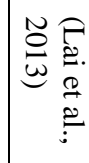 \\
\hline $\begin{array}{l}n \\
0 \\
\omega \\
\omega\end{array}$ & & & & & & & & & & \begin{tabular}{|l}
$z$ \\
0 \\
$\frac{5}{0}$ \\
$\frac{1}{0}$ \\
$\frac{0}{0}$ \\
0 \\
0
\end{tabular} & 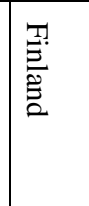 & 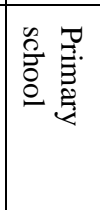 & 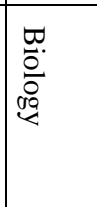 & 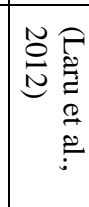 \\
\hline- & & & & & & & & $\star$ & & 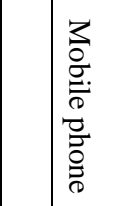 & 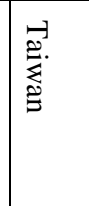 & 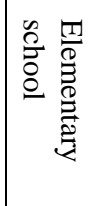 & 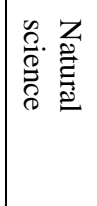 & 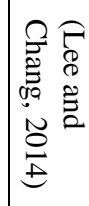 \\
\hline $\begin{array}{l}u \\
0 \\
0 \\
a\end{array}$ & & & & & & & & & & 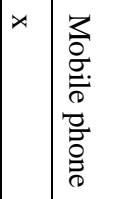 & 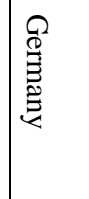 & 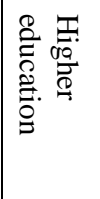 & 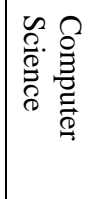 & 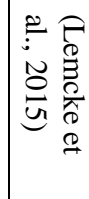 \\
\hline- & & & & & & & & & 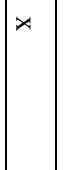 & $\underset{D}{\vec{D}}$ & 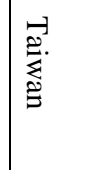 & 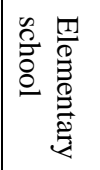 & 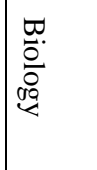 & 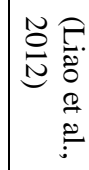 \\
\hline $\begin{array}{l}\tilde{N} \\
\overrightarrow{0}\end{array}$ & & & $\star x$ & & & & & & & 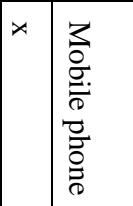 & 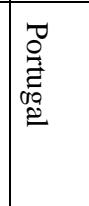 & 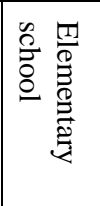 & 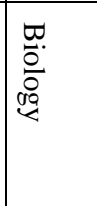 & 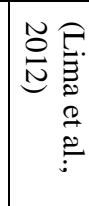 \\
\hline
\end{tabular}


OUTDOOR LEARNING WITH MOBILE TECHNOLOGY: A SYSTEMATIC REVIEW

\begin{tabular}{|c|c|c|c|c|c|c|c|c|c|c|c|c|c|c|c|c|}
\hline 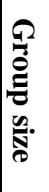 & 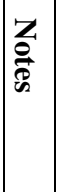 & 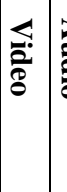 & 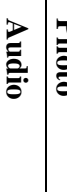 & $\overrightarrow{\bar{\sigma}}$ & 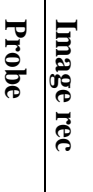 & 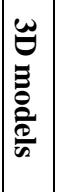 & & 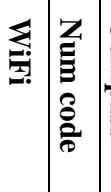 & 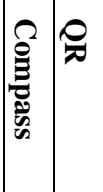 & $\underset{0}{\mathbf{z}}$ & 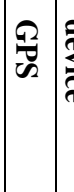 & 家 & 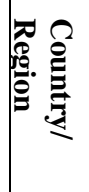 & 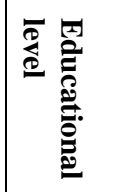 & 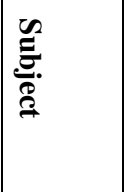 & 臺 \\
\hline- & & & & & & & & & & & $\begin{array}{ll}\times \\
\end{array}$ & $\begin{array}{l}3 \\
0 \\
0 \\
\frac{5}{0} \\
\frac{0}{0} \\
0 \\
0 \\
0\end{array}$ & 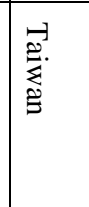 & 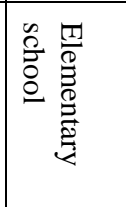 & 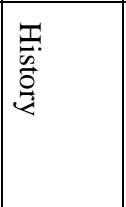 & 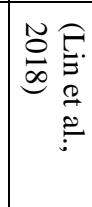 \\
\hline $\begin{array}{l}- \\
0 \\
0 \\
0 \\
u \\
u\end{array}$ & & & $\star$ & & & & $\star$ & & $\star$ & & & $\underset{D}{\vec{D}}$ & 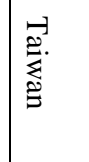 & 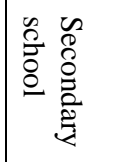 & 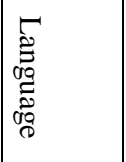 & 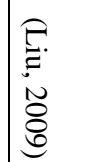 \\
\hline $\begin{array}{l}- \\
0 \\
0 \\
0 \\
a\end{array}$ & & $\star$ & & $\star$ & & & $x$ & & & $\times$ & & $\underset{D}{\vec{D}}$ & 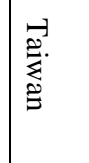 & 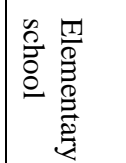 & 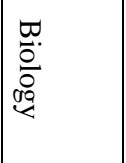 & 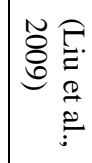 \\
\hline $\begin{array}{l}n \\
\overrightarrow{0} \\
\omega \\
\omega\end{array}$ & $\star$ & & & $\rtimes$ & & & & & & & $\times$ & $\underset{D}{\vec{D}}$ & 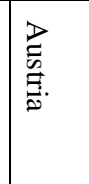 & 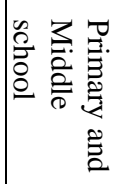 & 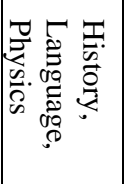 & 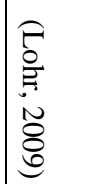 \\
\hline- & $x$ & & $\star x$ & $\rtimes$ & & & & & $x$ & & $x$ & $\begin{array}{l}3 \\
0 \\
\frac{0}{0} \\
\frac{0}{0} \\
\frac{0}{0} \\
\frac{0}{0}\end{array}$ & 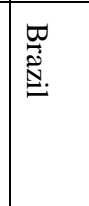 & 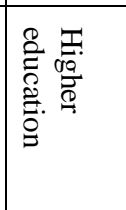 & 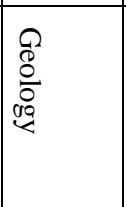 & 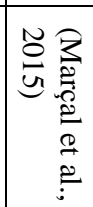 \\
\hline- & $\star x$ & & $\times>$ & $\star$ & & & & & & & 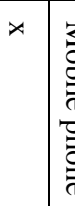 & 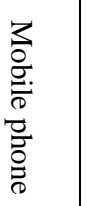 & ه. & 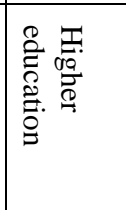 & 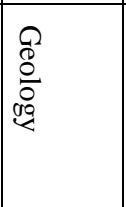 & 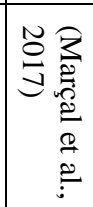 \\
\hline$N$ & 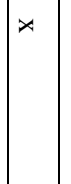 & & & & & & & & & & & $\frac{\overrightarrow{\tilde{\sigma}}}{\stackrel{\vec{\sigma}}{\sigma}}$ & $\begin{array}{l}\Xi \\
\infty \\
D\end{array}$ & 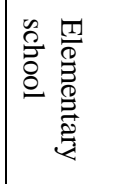 & 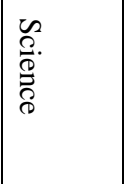 & 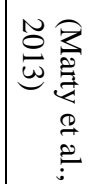 \\
\hline
\end{tabular}


IADIS International Journal on WWW/Internet

\begin{tabular}{|c|c|c|c|c|c|c|c|c|c|c|c|c|c|c|c|c|c|c|}
\hline 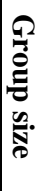 & 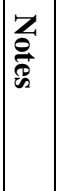 & 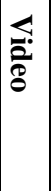 & 莗 & $\vec{\sigma}$ & 苟 & 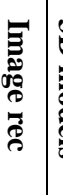 & 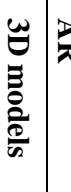 & $\mathbb{d}$ & 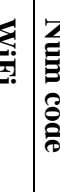 & 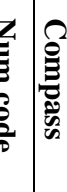 & $\stackrel{\rho}{\pi}$ & 접 & $\frac{2}{2}$ & 产 & 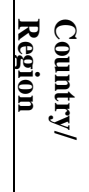 & 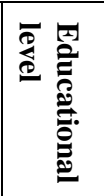 & 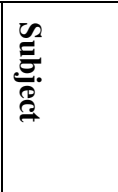 & | \\
\hline N & & & & & & & & & & & & & & $\begin{array}{l}3 \\
\frac{3}{0} \\
\frac{0}{0} \\
0 \\
\frac{0}{0} \\
0 \\
0\end{array}$ & 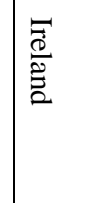 & 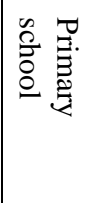 & 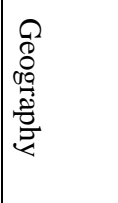 & 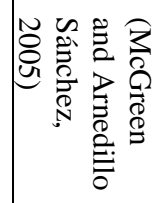 \\
\hline- & & & & & & & & & & & 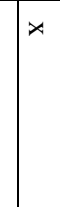 & & & 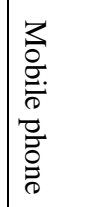 & 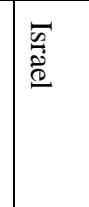 & 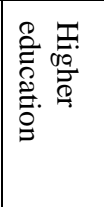 & 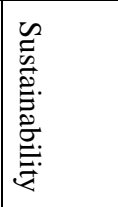 & 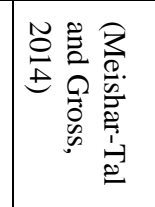 \\
\hline$\omega$ & & & & $\star$ & $x$ & & & & & & & & $x$ & $\vec{D}$ & 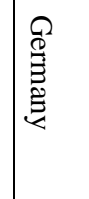 & 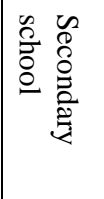 & 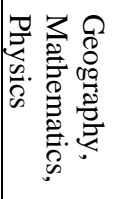 & 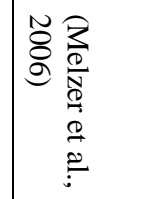 \\
\hline$\omega$ & & & & & & & & & & & $\star$ & & $x$ & $\begin{array}{l}3 \\
\frac{3}{0} \\
\frac{0}{0} \\
0 \\
\frac{0}{0} \\
\frac{0}{0}\end{array}$ & $\begin{array}{l}\frac{\pi}{2} \\
\hat{0} \\
\Xi_{2}\end{array}$ & 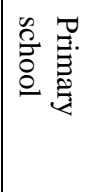 & 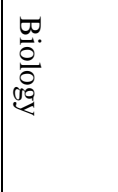 & 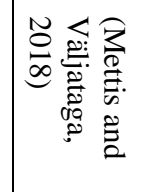 \\
\hline$a$ & $\star$ & & & $\star$ & & & & x & & & & & & $\begin{array}{l}\overrightarrow{\ddot{\sigma}} \\
\vec{\sigma}\end{array}$ & 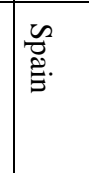 & 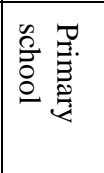 & 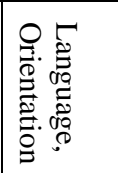 & 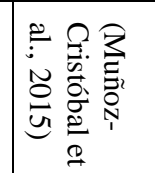 \\
\hline- & & & & & & & & & & & $\star$ & & & 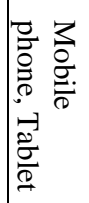 & 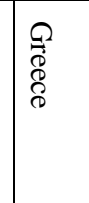 & 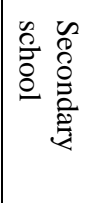 & 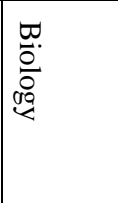 & 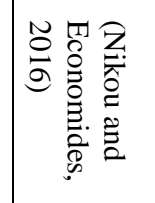 \\
\hline$\omega$ & & $\star$ & & $\star$ & & & & & x & & $x$ & & & 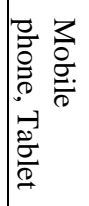 & $\begin{array}{l}\infty \\
\sum_{\infty} \\
0 \\
ٍ \\
ٍ\end{array}$ & 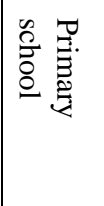 & 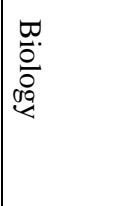 & 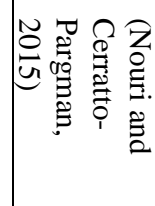 \\
\hline
\end{tabular}


OUTDOOR LEARNING WITH MOBILE TECHNOLOGY: A SYSTEMATIC REVIEW

\begin{tabular}{|c|c|c|c|c|c|c|c|c|c|c|c|c|c|c|c|c|c|c|}
\hline 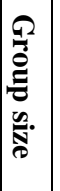 & 盛 & \begin{tabular}{|c|} 
\\
$\vdots$ \\
\hdashline \\
\end{tabular} & 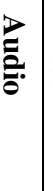 & $\vec{\sigma}$ & 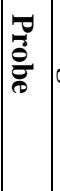 & 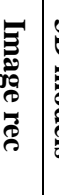 & 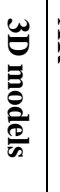 & $\vec{J}$ & 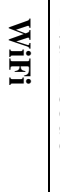 & 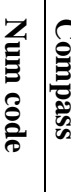 & 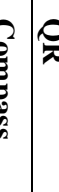 & $\frac{\pi}{\frac{\pi}{2}}$ & $\frac{9}{2}$ & 告 & 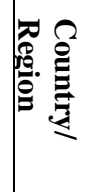 & 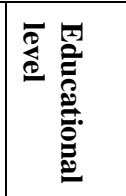 & 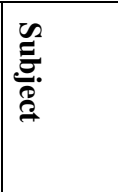 & 尝 \\
\hline$\omega$ & & & & & & & & & & & & & $\times$ & 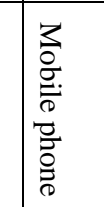 & 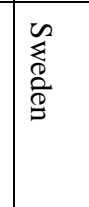 & 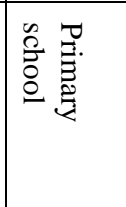 & 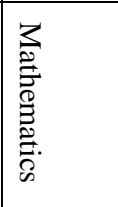 & 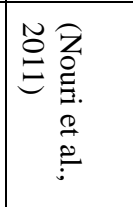 \\
\hline- & $\star$ & & $x$ & $\star$ & & & & & & & & & $\star$ & $\underset{D}{\Xi}$ & 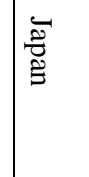 & 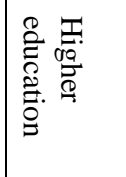 & 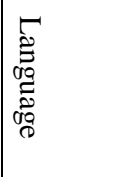 & 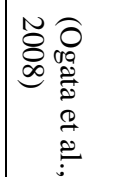 \\
\hline \begin{tabular}{l|}
$u$ \\
$\overrightarrow{0}$ \\
$a$
\end{tabular} & & & & & & & & & & & x & $4 \times$ & & $\begin{array}{l}3 \\
0 \\
\frac{0}{0} \\
\overline{0} \\
\frac{0}{0} \\
\overline{0} \\
\overline{0}\end{array}$ & $\begin{array}{l}\breve{\widetilde{\Xi}} \\
\stackrel{\mathscr{\Xi}}{\Xi}\end{array}$ & 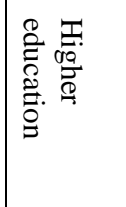 & 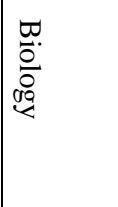 & 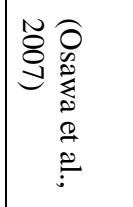 \\
\hline$N$ & & & & & & & & & & & & & $\times$ & 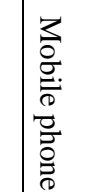 & 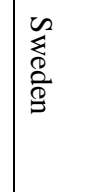 & 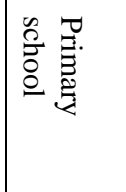 & 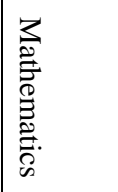 & 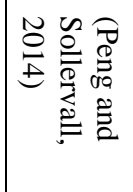 \\
\hline- & & & & & & & & & & & & & & $\underset{ઇ}{\Xi}$ & 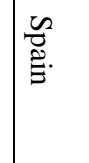 & 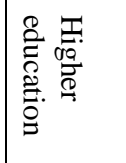 & 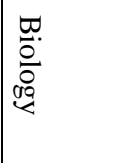 & 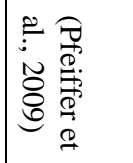 \\
\hline \begin{tabular}{|l|} 
\\
$\overrightarrow{0}$ \\
$u$ \\
\end{tabular} & & & & $x$ & & & $\star$ & $\star$ & & $x$ & 4 & & & 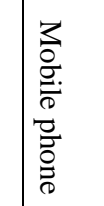 & 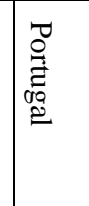 & 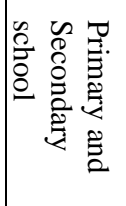 & 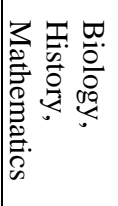 & 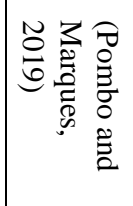 \\
\hline- & & & $\rtimes$ & $\star$ & & & & & & & & & & $\begin{array}{l}3 \\
\frac{3}{0} \\
\overline{0} \\
\frac{0}{0} \\
\frac{0}{0} \\
0\end{array}$ & 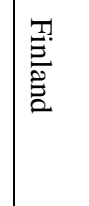 & 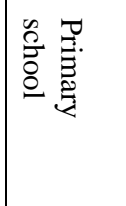 & 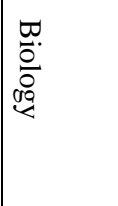 & 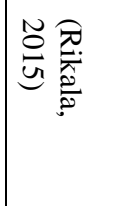 \\
\hline
\end{tabular}


IADIS International Journal on WWW/Internet

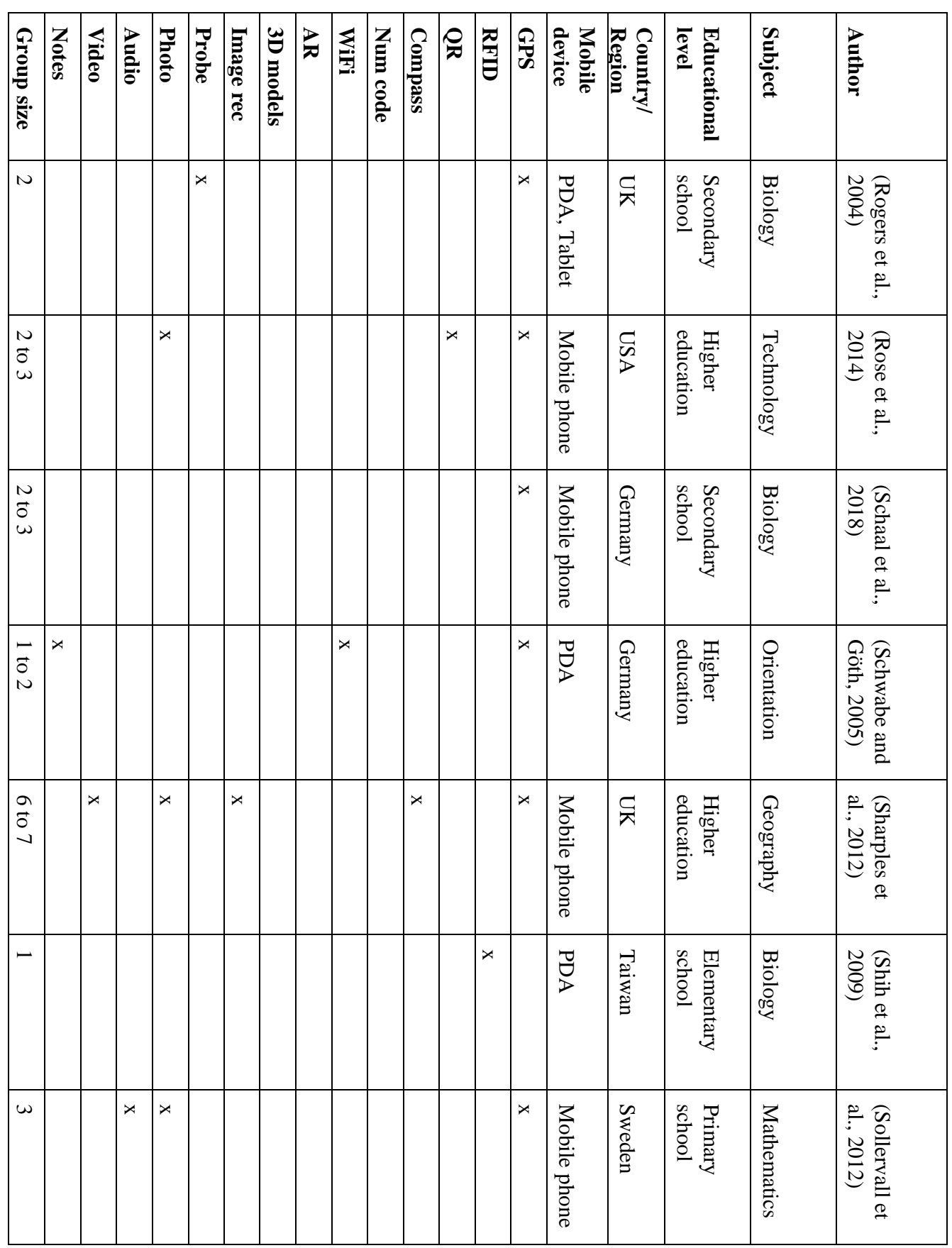


OUTDOOR LEARNING WITH MOBILE TECHNOLOGY: A SYSTEMATIC REVIEW

\begin{tabular}{|c|c|c|c|c|c|c|c|c|c|c|c|c|c|c|c|}
\hline 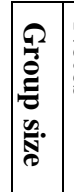 & 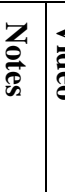 & & & & 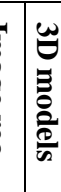 & $\mathbb{Z}$ & I & 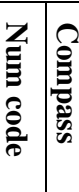 & : & $\begin{array}{ll}0 \\
8\end{array}$ & 产 & 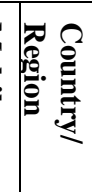 & 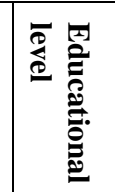 & 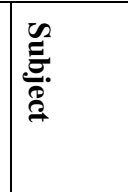 & 黪 \\
\hline-1 & & & 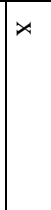 & & & & & & & & 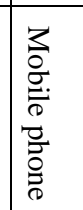 & 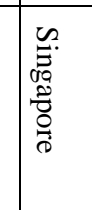 & 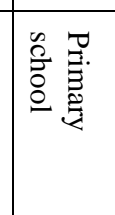 & 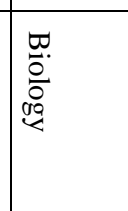 & 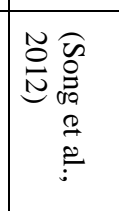 \\
\hline $\begin{array}{l} \\
w \\
w\end{array}$ & & & & & & & & & 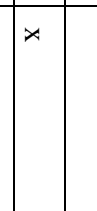 & $\star$ & \begin{tabular}{|l}
$z$ \\
$\frac{z}{0}$ \\
$\frac{0}{0}$ \\
0 \\
0 \\
0 \\
0 \\
0
\end{tabular} & 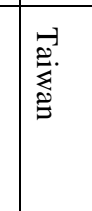 & 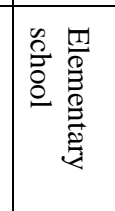 & 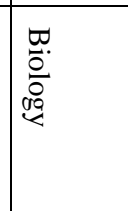 & 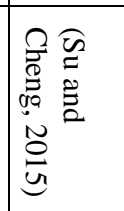 \\
\hline \begin{tabular}{ll}
$t$ \\
\multirow{0}{*}{} \\
un
\end{tabular} & & & & $x$ & & & & & & $\times$ & 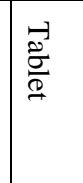 & 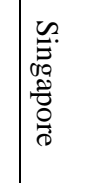 & 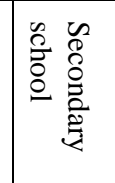 & 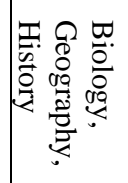 & 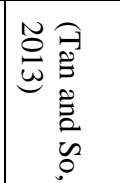 \\
\hline+ & & & $\star *$ & & & & & & & & $\underset{D}{D}$ & 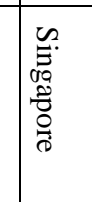 & 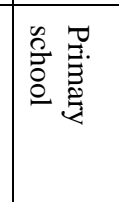 & 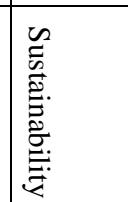 & 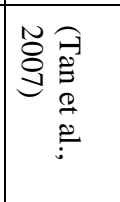 \\
\hline \begin{tabular}{|l|}
- \\
\end{tabular} & & & & & x & $x$ & & & & $\star$ & 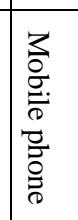 & $\vec{H}$ & 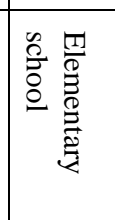 & 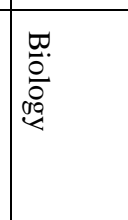 & 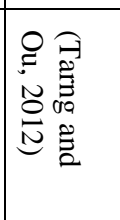 \\
\hline \begin{tabular}{|l|}
$N$ \\
$w$ \\
$w$
\end{tabular} & & & & & $\star$ & & & & & × & 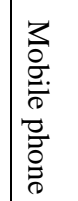 & 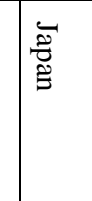 & 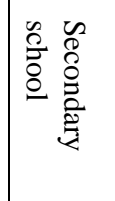 & 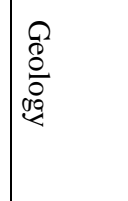 & 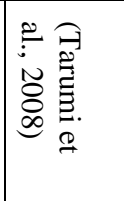 \\
\hline \begin{tabular}{|l|}
+ \\
\end{tabular} & & & & * & & & & & & $\star$ & 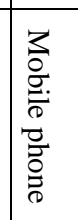 & $\stackrel{\hookrightarrow}{\pi}$ & 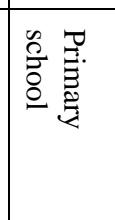 & 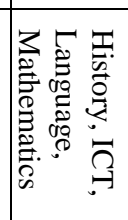 & 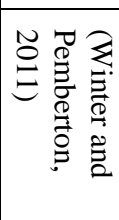 \\
\hline
\end{tabular}


IADIS International Journal on WWW/Internet

\begin{tabular}{|c|c|c|c|c|c|c|c|c|c|c|c|c|c|c|c|c|}
\hline 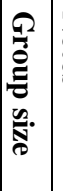 & 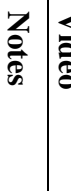 & 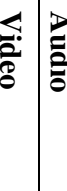 & : & $\frac{7}{3}$ & 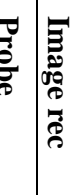 & 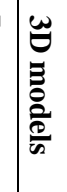 & 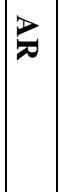 & 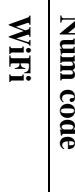 & 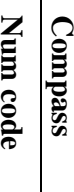 & ? & 尩 & 商 & 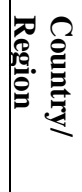 & 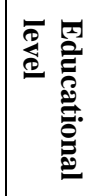 & 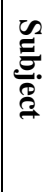 & 莺 \\
\hline- & & & $\star x$ & & & & & & & & & $\begin{array}{l}3 \\
0 \\
0 \\
\frac{5}{0} \\
0 \\
0 \\
0 \\
0 \\
0\end{array}$ & 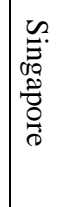 & 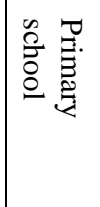 & 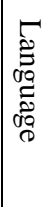 & 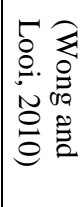 \\
\hline- & & & $\star$ & & $x$ & & & & & & & 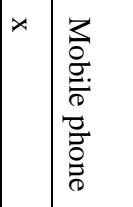 & $\subseteq$ & 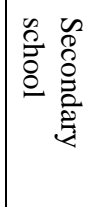 & 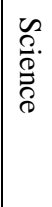 & 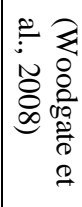 \\
\hline- & & & & & & & & & & 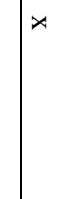 & & $\begin{array}{l}3 \\
\frac{3}{0} \\
\frac{0}{0} \\
0 \\
\frac{0}{0} \\
0 \\
\overline{0}\end{array}$ & 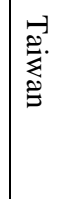 & 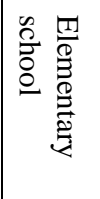 & 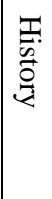 & 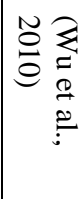 \\
\hline $\begin{array}{l}u \\
\overrightarrow{0} \\
a \\
a\end{array}$ & & & $x$ & & & & & & & & & 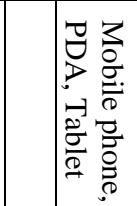 & 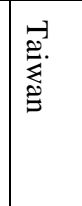 & 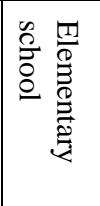 & 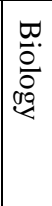 & 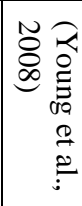 \\
\hline If & & $\star$ & $x$ & & & & & & & & & 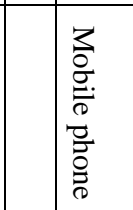 & 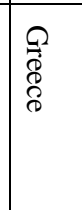 & 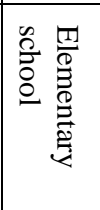 & 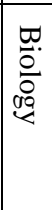 & 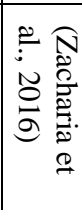 \\
\hline
\end{tabular}

